\title{
11. Berlin-Gespräche mit den USA von Januar bis Oktober 1962
}

\author{
Instruktionen des Außenministeriums
}

Mitte November 1961 entwarf das sowjetische Außenministerium neue Instruktionen für die Vier-Mächte-Verhandlungen, mit deren baldigem Beginn man rechnete. Wie 1959 in Genf wurde die Teilnahme beider deutscher Staaten gefordert. Ohne die Deutschen, so lautete die Begründung, lasse sich keine abschließende Übereinkunft treffen. Falls hierüber durchaus keine Übereinkunft zu erzielen sei, wollte man das Verlangen zunächst fallenlassen, jedoch sich das Recht vorbehalten, darauf wieder zurückzukommen. Eine rasche Übereinkunft galt als sehr wichtig. Ein Aufschub sei nicht akzeptabel. Die Verhandlungen sollten schon im Dezember beginnen. Der westlichen Seite war dann sofort der „grundsätzliche“ Standpunkt der UdSSR vorzulegen. Dabei war vor allem zu betonen, daß nur eine West-Berlin-Regelung in Betracht komme, die auf dem Friedensvertrag beruhe und die uneingeschränkt souveräne Verfügungsgewalt der DDR über die Zugangswege festlege. Sofern die Westmächte Skepsis hinsichtlich der ostdeutschen Bereitschaft äußerten, unbehinderten Transit zu gewähren, sollte der Zweifel durch Aussagen eines anzuhörenden DDR-Vertreters ausgeräumt werden.

Falls die westlichen Delegationen zum Friedensschluß mit der DDR nicht bereit seien, sollten die sowjetischen Unterhändler deutlich machen, das Besatzungsrecht werde dann eben ohne Vertrag aufgehoben. Etwaigen Versuchen, nicht nur West-, sondern auch Ost-Berlin zum Gegenstand der Vereinbarung zu machen, war entgegenzuhalten, die Hauptstadt der DDR könne keinesfalls einbezogen werden. Ebensowenig sollte eine Erörterung der Abriegelungsmaßnahmen vom August 1961 zulässig sein. Es gehe um ein Recht der souveränen DDR, über das die Vier Mächte nicht befinden könnten. Ein analoges Recht für West-Berlin, über sein Schicksal ohne fremde Einmischung zu entscheiden, war freilich nicht vorgesehen. Wenn die USA vorschlügen, die dortige Bevölkerung über das ihr zugedachte Freistadt-Statut abstimmen zu lassen, war einzuwenden, die Liquidierung des Besatzungsregimes und der Truppenpräsenz sei eine Vier-MächteAngelegenheit. Auch ein Plebiszit der Deutschen darüber, ob man den Friedensvertrag wolle, durfte nicht zugelassen werden. Auch hatten die sowjetischen Unterhändler jeden Versuch zu verhindern, die Einigung über Deutschland und Berlin hinauszuschieben. Demnach sollte eine Diskussion selbst über das - in Moskauer Sicht sehr wichtige - Thema der „europäischen Sicherheit“ nur dann erlaubt sein, wenn davon keine Verzögerung für Friedensvertrag und Freistadtregelung zu befürchten war. Zugleich hatten die Vertreter der UdSSR darauf zu 
bestehen, daß eine West-Berlin-Vereinbarung keinesfalls nur vorläufiger Art sein dürfe. ${ }^{1}$

Der Weisungsentwurf des Außenministeriums war von vornherein unrealistisch. Das betraf den Termin, die Gesprächsebene und die Konzessionsbereitschaft der anderen Seite. Es dauerte längere Zeit, bis die amerikanische Regierung überhaupt zu einem weiteren Austausch der Standpunkte bereit war. Vor Aufnahme der Gespräche zwischen Thompson und Gromyko setzte sie mit Rücksicht auf die Verbündeten durch, daß der ins Auge gefaßten Vier-Mächte-Konferenz nach wie vor ein bilateraler Dialog zur Klärung der Erfolgsaussichten vorauszugehen hatte. ${ }^{2}$ In der ersten Unterredung zwischen Gromyko und Thompson am 2. Januar 1962 stellte der amerikanische Diplomat als zentrales Erfordernis die Regelung des Zugangs nach West-Berlin heraus und nannte dafür zwei Optionen. Ein dem Westen eingeräumter Korridor oder ein paritätisch aus Vertretern von Ost und West gebildetes Organ sollten einen behinderungsfreien Transitverkehr gewährleisten. Wenn sich die UdSSR für das Organ entscheide, wolle man ihren Wünschen entgegenkommen und neben Beauftragten der Bundesrepublik und West-Berlins auch Repräsentanten der DDR und Ost-Berlins akzeptieren. Die Aufgabe solle sein, die Autobahnstrecke verwalten und die Sicherheit des Luftverkehrs zu gewährleisten. Thompson betonte, wenn die sowjetische Seite dazu bereit sei, könnten auch ihre sonstigen Wünsche geprüft werden. Gromyko bezeichnete den Vorschlag als völlig unannehmbar. Der Zugang sei nur ein Teilproblem, dessen Lösung von der Friedensregelung und der damit verbundenen Liquidierung der Überreste des Zweiten Weltkrieges abhänge. Notwendig seien vor allem die Beseitigung der besatzungsrechtlichen Grundlagen, die uneingeschränkte Respektierung der ostdeutschen Souveränität und die Anerkennung der DDR. Erst wenn man sich darauf geeinigt habe, könne man an eine Übereinkunft über andere Fragen denken. ${ }^{3}$

\section{Chruschtschows Aktionsprogramm}

Gromyko stellte gegenüber dem Parteipräsidium mit Befriedigung fest, die Amerikaner seien bereit, „mit der Souveränität der DDR praktisch zu rechnen“, und regte an, die Behandlung des Zugangs ausdrücklich von einer vorherigen Einigung über Friedensvertrag und Freistadt-Status abhängig zu machen. Die Position der UdSSR in diesen beiden Punkten lasse sich klarstellen durch Entwürfe für ein West-Berlin-Statut und ein Garantieprotokoll, das vor allem den Zugang behandele. Die zu erwartende Frage der Amerikaner, ob die Regelung einen völlig freien Verkehr gewährleiste, solle mit dem Hinweis auf die notwendige Respektierung

1 Ukazanija k peregovoram SSSR s SŠA, Angliej i Franciej o zaključenii germanskogo dogovora i normalizacii položenija v Zapadnom Berline, 17. 11. 1961, AVPRF, 0742, 6, 46, 36, Bl. 82-91.

2 Department of State an die US-Botschaft in Moskau, 28. 12. 1961, in: Foreign Relations of the United States 1961-1963 [FRUS], Bd. XIV: Berlin Crisis 1961-1962, Washington 1993, S. 709-713.

3 A. Gromyko an das ZK der KPdSU, 5. 1. 1962, AVPRF, 0129, 46, 346, Bl. 1-3. Vgl. Telegram From the Embassy in the Soviet Union to the Department of State, 2.1. 1962, FRUS 1961-1963, XIV, S. 720-724; Aktenvermerk über Frühstück bei Gromyko am 5.1. 1962, PA-MfAA, C 858, B1. 2832. 
der DDR-Souveränität beantwortet werden. ${ }^{4}$ Auch wenn der Außenminister das westliche Verlangen nach ungehindertem Zugang nur taktisch und mehr zum Schein als ernstlich berücksichtigen wollte, war Chruschtschow nicht einverstanden. Nach seiner Ansicht lief jedes Eingehen auf das Verlangen nach West-BerlinPräsenz und nach einem Zugangskorridor, von dessen Erfüllung die USA die angebotenen Konzessionen abhängig gemacht hatten, auf eine Verschlechterung des Status quo hinaus. Um nicht das geringste Risiko in dieser Richtung einzugehen, erklärte er am 8. Januar den Führungsmitgliedern, ergebnisorientierte Verhandlungen kämen nicht in Betracht. Nur zwecks Ausübung ständigen Drucks sollten die Gespräche fortgeführt werden. ${ }^{5}$

Chruschtschow begründete seinen Standpunkt damit, der Westen sei noch nicht auf eine Regelung vorbereitet. Die „reaktionären“ Tendenzen seien noch sehr stark, und aufgrund des militärischen Gleichstands habe die UdSSR keinen Verhandlungsvorteil. Weil die Umstände keine erfolgversprechenden Pressionen zuließen, seien Friedensvertrag und Neutralisierung West-Berlins vorerst unerreichbar. Ein zusätzliches Problem sah der Parteichef in Kennedys vermeintlicher Persönlichkeitsschwäche. Diese möge in Verhandlungen nützlich sein, stelle aber auch ein Risiko dar, denn der Präsident genieße bei den Großkapitalisten und in der Öffentlichkeit seines Landes keine Autorität. Er werde nicht als Führer akzeptiert. In den USA drohe daher eine Diktatur sowjetfeindlicher Kräfte, die jede Einigung in unerreichbare Ferne rücken würde. Diese Gefahr, so blieb unausgesprochen, wäre im Konfrontationsfall besonders groß. Chruschtschow hielt zudem die ökonomischen Verhältnisse für nachteilig. Die Sowjetunion sei zwar hinreichend autark, um sich eine Konfrontation leisten zu können, doch seien die Tschechoslowakei und vor allem die DDR auf die Lieferungen aus der Bundesrepublik angewiesen. Polen mache sich von den materiellen Vorteilen abhängig, die ihm die Amerikaner gewährten. Die Wirtschaftsplanung der sozialistischen Staaten müsse sich auf den RGW-Bereich umorientieren. Das werde von Ost-Berlin zwar immer wieder zugesagt, faktisch aber nicht durchgeführt. Die Schwäche der Verbündeten schlage auf die UdSSR durch. Wann immer vereinbarte Lieferungen ausblieben und Bedarf an Hilfe bestehe, müsse sie die Lasten tragen. Unter diesen Voraussetzungen könne man einen Zusammenstoß mit dem Westen nicht wagen. ${ }^{6}$

Chruschtschow war überzeugt, daß die UdSSR ein rasches ökonomisches Wachstum aufweise und das sozialistische Lager seine Schwäche durch koordinierte Planung überwinden könne. Er gab der Erwartung Ausdruck, daß der Sozialismus insgesamt auf dem Vormarsch sei und daß sich das Kräfteverhältnis un-

4 A. Gromyko an das ZK der KPdSU, 5. 1. 1962, AVPRF, 0129, 46, 346, Bl. 3-5.

5 Protokoll der Sitzung des Präsidiums des ZK der KPdSU, 8. 1. 1962, in: A. A. Fursenko (otv. red.), Archivy Kremlja. Prezidium CK KPSS 1954-1964. Černovye protokol'nye zapisi zasedanij. Stenogrammy, Moskau 2003, S. 535; Stenographische Niederschrift der Sitzung des Präsidiums des ZK der KPdSU, 8. 1. 1962, ebd., S. 537.

6 Protokoll der Sitzung des Präsidiums des ZK der KPdSU, 8. 1. 1962, ebd., S. 535; Stenographische Niederschrift der Sitzung des Präsidiums des ZK der KPdSU, 8. 1. 1962, ebd., S. 537f., 539-541. Das Urteil über Kennedy und die Gefährdung seiner Führungsrolle gingen auf ein Papier zurück, das Chruščëv kurz zuvor unterbreitet worden war: A. A. Arzumanjan an N. S. Chruščëv, 3. 1. 1962, RGANI, 5, 30, 398 (rolik 95), Bl. 68-85. 
aufhaltsam zu seinen Gunsten verändere. Er hielt daher Kompromisse für unklug. Später lasse sich alles ohne Mühe erreichen. Deswegen dürfe man keine Vereinbarung schließen, welche die erhobenen Forderungen einschränke. Eine Regelung, die als Preis für Konzessionen die Präsenz und den Zugang der Westmächte bestätigte, war demnach nicht als Teilerfolg, sondern als Verschlechterung der bestehenden Lage anzusehen, die den künftigen Totalerfolg verhinderte. Daraus leitete Chruschtschow die Schlußfolgerung ab, man solle keine Ergebnisse von den Verhandlungen erwarten, sondern sie als Instrument des Drucks einsetzen. Die Schließung der offenen DDR-Grenze habe dafür die Voraussetzungen geschaffen. Sei der Knochen bisher im eigenen Hals gewesen, so stecke er nun umgekehrt im Hals des Westens. Dieser habe mit wachsenden Schwierigkeiten zu kämpfen, während man selbst alles Wichtige wie die Anerkennung der deutschen Zweistaatlichkeit und klare Grenzen bereits erreicht habe und lediglich auf das weitere Anwachsen des eigenen Potentials zu warten brauche. Darum, so meinte Chruschtschow in Übereinstimmung mit den Führungskollegen, solle man die BerlinFrage nicht forcieren. Vor allem dürfe man kein Kriegsrisiko eingehen, denn die Folgen eines bewaffneten Konflikts entzögen sich rationaler Berechenbarkeit.7

Die Pressionen, die von den Berlin-Gesprächen ausgingen, und die Schwierigkeiten, die sich aufgrund der im August 1961 geschaffenen Lage entwickelten, sollten die Westmächte allmählich von der Notwendigkeit eines Eingehens auf die sowjetischen Vorstellungen überzeugen. West-Berlin, so kalkulierte Chruschtschow, habe für die Gegenseite die frühere Bedeutung verloren und sei zu einem "Geschwür" geworden, dessen Existenz ständig enorme Mittel verschlinge. Solange es kein Abkommen mit UdSSR und DDR gebe, sei die dortige politische Lage labil und lasse keine wirtschaftliche Entwicklung zu. Die Bevölkerung verliere dadurch immer mehr das Vertrauen in die Zukunft. ${ }^{8}$ Die Stadt lasse sich höchstens zehn Jahre lang halten. ${ }^{9}$ Danach werde sie „verdorrt“ sein. Nur durch Abschluß des Friedensvertrages, Umwandlung in eine „Freie Stadt“ und Herstellung stabiler Verhältnisse könne sie „eine Perspektive für ihre weitere Entwicklung“" gewinnen. ${ }^{10}$ Solange die Spannung anhalte, habe West-Berlin „keine Aussicht auf Entfaltung". Chruschtschow verließ sich darauf, daß unter den bestehenden Bedingungen der notwendige Kapitalzufluß ausbleibe und die Bevölkerung in Mutlosigkeit versinke. Diesen Effekt wollte er durch ein Vorgehen verstärken, das der sowjetischen „Unzufriedenheit Ausdruck“ gebe. ${ }^{11}$

7 Protokoll der Sitzung des Präsidiums des ZK der KPdSU, 8. 1. 1962, ebd., S. 535 f.; Stenographische Niederschrift der Sitzung des Präsidiums des ZK der KPdSU, 8. 1. 1962, ebd., S. 537-549. Vgl. die Darstellung bei A. A. Fursenko, Kak byla postroena berlinskaja stena, in: Istoričeskie zapiski, 4/2001 (122), S. 86 f.

8 Gespräch V. S. Semënov - O. Winzer, 6. 4. 1962, AVPRF, 0742, 7, 51, 4, Bl. 30. Vgl. I. Kabin an das ZK der KPdSU, 27. 2. 1962, RGANI, 5, 49, 489 (rolik 9019), Bl. 51-55.

9 Vermerk über die Besprechung Chruščëv - Ulbricht am 26. 2. 1962, 7. 3. 1962, PA-MfAA, G-A 478, Bl. 49.

10 Gespräch Chruščëvs mit amerikanischen Journalisten, 13. 7. 1962, in: Dokumente zur Deutschlandpolitik, IV, 8/2, S. 846.

11 Aufzeichnung ohne Überschrift und Datum (handschriftlich hinzugefügt: 10. 8. 1962), LArchB, B Rep. 002, Nr. 7993b, B1. 627. 


\section{Beginn der Gespräche mit den Amerikanern}

Gromyko erhielt von der sowjetischen Führung den Auftrag, auf Erfüllung der Forderungen nach Beseitigung der westlichen Präsenz in West-Berlin, Aufhebung des Beatzungsregimes und Freistadt-Regelung zu bestehen, bevor andere Fragen erörtert werden könnten. Er legte Botschafter Thompson am 12. Januar entsprechende Entwürfe vor und bestand darauf, daß dem Verlangen ohne Abstriche entsprochen werden müsse. Vor allem dürften die West-Berliner Verhältnisse allein auf Vereinbarungen hierüber beruhen; von westlichen Rechtsansprüchen könne dabei keine Rede sein. Der sowjetische Außenminister lehnte jede Bezugnahme auf Gesamt-Berlin strikt ab und bestand auf einer „echten“, das heißt uneingeschränkten Respektierung der ostdeutschen Souveränität. Er äußerte Bedauern darüber, daß es die USA ablehnten, sich in Ost-Berlin um die Gewährung von Transitrechten zu bemühen, wie es die UdSSR in Bonn getan habe. Das Argument setzte voraus, daß die Amerikaner keinen Anspruch auf Durchfahrt hatten. Diese These diente offenkundig dem Zweck, Ablehnung zu provozieren, die dann auch prompt erfolgte. ${ }^{12}$ Das Gespräch bewegte sich nicht von der Stelle. ${ }^{13}$

Chruschtschow suchte den Forderungen durch einen Appell an Kennedy Nachdruck zu verleihen. Er ließ ihn wissen, daß er zusammen mit ihm über den entmutigenden Auftakt der Unterredungen besorgt sei. Der Präsident müsse seine Haltung völlig ändern. Die Position, die Thompson vorgetragen habe, sei nichts als eine Wiederholung dessen, was schon sein Vorgänger Eisenhower, Bundeskanzler Adenauer und andere westliche Führer gesagt hätten. Demnach solle die UdSSR durch ihre Unterschrift die momentane Lage verewigen, das heißt zur Aufrechterhaltung des Besatzungsregimes in West-Berlin beitragen. Das erklärte der Kremlchef für undenkbar, denn das wäre ein Schritt nicht nach vorne, sondern zurück. Dem könne die Sowjetunion natürlich nicht zustimmen. Chruschtschow forderte Kennedy auf, sich zur Erörterung der von Gromyko unterbreiteten Entwürfe eines Freistadtstatuts und eines Garantieprotokolls bereitzufinden. Die Vorschläge seien für niemanden nachteilig. Die USA aber wollten ein „Diktat“, eine „Politik ,von der Position der Stärke aus““. Das habe schon bei Dulles keinen Erfolg gehabt, werde aber nach wie vor versucht den „enormen Veränderungen“ zum Trotz, die in der Welt eingetreten seien. Die UdSSR müsse sich um des Friedens willen dagegen zur Wehr setzen. Es wäre am besten, wenn die Amerikaner Commonsense und Nüchternheit bewiesen und eine Normalisierung der Beziehungen anstrebten, statt an den Spannungsherden festzuhalten. ${ }^{14}$

Kennedy ließ sich durch den vorwurfsvollen Appell des Kremlchefs nicht zum Nachgeben bewegen. Am 31. Januar erklärte er dessen Schwiegersohn Adshubej,

12 Telegram From the Embassy in the Soviet Union to the Department of State, 12. 1. 1962, in: FRUS 1961-1963, XIV, S. 751-755; Gespräch Gromyko - Thompson am 12.1. 1962 und die Entwürfe der UdSSR für ein Freistadtstatut und eine Garantieerklärung (sowjetische Niederschrift in tschechischer Übersetzung), in: Michal Reiman/Petr Luňák (Hrsg.) Studená válka. Sovětské dokumenty v českých archivech, Brünn 2000, S. 330-340.

13 Aktenvermerk Krolikowski über Gespräch mit Botschaftsrat Žiljakov am 19. 1. 1962, PA-MfAA, G-A 478, Bl. 26.

14 Message to Attorney General Kennedy [aus Moskau zur Übermittlung an den Präsidenten], 18.1. 1962, in: FRUS 1961-1963, XIV, S. 763-766. 
die beiderseitigen Positionen seien unvereinbar. Es wäre aber fatal, wenn es zu keiner Einigung käme. Gromyko und Thompson sollten sich um Fortschritte in Einzelfragen bemühen. Es wäre sinnlos, sich über freien Zugang zu unterhalten, wenn nicht klar sei, wie die UdSSR die angeregten „akzeptierten internationalen Standards" auslege. ${ }^{15}$ Am gleichen Tag sprach der Präsident auf einer Pressekonferenz die Hoffnung aus, daß die vielfältigen Gespräche und Sondierungen mit der sowjetischen Seite „zu einem glücklichen Resultat führen“ würden, räumte aber ein, daß in der Berlin- und Deutschland-Frage „wesentliche Fortschritte“ nicht erreicht worden seien. ${ }^{16}$

Die USA zeigten damit weiterhin deutliches Interesse an einer Übereinkunft. Aus Moskauer Sicht sollten sie aber keine eigenen Vorstellungen formulieren, sondern nur die sowjetischen Forderungen als Gesprächsgrundlage akzeptieren. Gromyko warf Thompson am 1. Februar vor, dessen Regierung meine es nicht ernst, wenn sie Vorschläge vorlege, deren Ablehnung durch die UdSSR ihr bekannt sei, und die Zugangsfrage in den Mittelpunkt stelle, die doch nur ein Teilproblem sei. Als der amerikanische Botschafter erklärte, im Falle eines einseitigen Friedensvertragsabschlusses würden die Westmächte nicht der Gewalt weichen, entgegnete er scharf, wenn sie Krieg wollten, könnten sie ihn haben. ${ }^{17}$ Auch am 9. Februar kam man nicht weiter. ${ }^{18}$ Chruschtschow meinte gar, der Meinungsaustausch mit Thompson sei „ein Schritt zurück gegenüber früheren Gesprächen“.19

\section{Attacken gegen die West-Berliner Luftkorridore}

Wie Chruschtschow vorausgeplant hatte, endete die Politik der kategorischen Forderungen in einer Sackgasse. Er suchte daraufhin den Druck zu verstärken, ohne freilich das Konfrontationsrisiko einzugehen, das bei Abschluß eines Separatvertrags drohte. Aktionen gegen die Luftzugänge West-Berlins, die selbst während der Blockade von 1948/49 unterblieben waren, sollten den Westen zermürben. Der sowjetische Vertreter in der Sicherheitszentrale der Vier Mächte erklärte am 8., 9. und 12. Februar 1962, wegen militärischer „Übungsflüge“ lasse sich jeweils für einige Stunden die Sicherheit der westlichen Flugzeuge in den Luftkor-

15 Memorandum of Conversation, 31. 1. 1962, ebd., S. 780-783.

16 Aus der Pressekonferenz des Präsidenten Kennedy, 31. 1. 1962 in: Dokumente zur Deutschlandpolitik, a.a.O., IV, 8/2, S. $112 \mathrm{f}$.

17 Kratkaja informacija o vstreče Ministra inostrannych del A. A. Gromyko s poslom SŠA v Moskve Tompsonom [1. 2. 1962], AAN, KC PZPR XI A/81, Bl. 26-29; Notizen über das Treffen Gromyko/Thompson am 1. Februar 1962, PA-MfAA, G-A 188, Bl. 1-4; Proekt kratkoj informacii o vstreče Ministra inostrannych del A. A. Gromyko s poslom SŠA v Moskve Tompsonom [1.2. 1962], AVPRF, 0129, 46, 346, 56, Bl. 63; Kurze Information über Zusammenkunft Gromyko Thompson am 1.2. 1962, PA-MfAA, C 858, Bl. 57 f.; Telegram From the Embassy in the Soviet Union to the Department of State, 1. 2. 1962, in: FRUS 1961-1963, Bd. IV, S. 784-788.

18 Zajavlenie ministra inostrannych del poslu SSA v Moskve Tompsonu, 7. 2. 1962 [Formulierungsdatum], AVPRF, 0129, 46, 346, 12, Bl. 7-14/AAN, KC PZPR XI A/81, Bl. 15-25; Telegram From the Embassy in the Soviet Union to the Department of State, 9. 2. 1962, in: FRUS 1961-1963, XIV, S. 797-800. Wiedergabe der Erklärung Gromykos gegenüber Thompson vom 9. 2. 1962 (tschech. Übers.) in: M. Reiman/P. Luňák, a.a.O., S. 351-359.

19 Vermerk über Besprechung Chruščëv - Ulbricht in Moskau am 26. 2. 1962, 7. 3. 1962, PA-MfAA, G-A 478, Bl. 50 . 
ridoren nicht gewährleisten. Sein amerikanischer Kollege gab daraufhin zu Protokoll, er gehe mit den beiden anderen Repräsentanten des Westens davon aus, daß bei den angekündigten Flügen die festgelegten Regeln auch weiterhin eingehalten würden und die westlichen Flugzeuge daher die Korridore vertragsgemäß benutzen könnten. Er verband damit die Forderung, daß die sowjetischen Flugpläne vorgelegt werden müßten. Das wurde mit der Begründung abgelehnt, daß sich der Flugsicherheitsdienst der UdSSR „nicht mit den Problemen der Koordination der Flüge über dem Territorium der DDR zwecks deren Sicherheitsgewährleistung“ befasse. ${ }^{20}$ Damit wurde die Sicherheit der einzig völlig unkontrollierten Außenverbindung West-Berlins in Frage gestellt. Der Oberbefehlshaber der Streitkräfte der UdSSR in Deutschland ließ große Militärtransportmaschinen zu Flügen durch die Luftkorridore starten und bedrohte auf diese Weise den sie benutzenden westlichen Linienverkehr. Das richtete sich am 9. Februar unter anderem gegen ein amerikanisches Flugzeug, von dem bekannt war, daß zu den Passagieren General Clay und Bürgermeister Brandt gehörten.21

Obwohl die Vertreter der USA vor Ort sofort den wirksamen Gebrauch des Zugangs durch die Luft insgesamt gefährdet sahen,22 spielte Washington die Sache zunächst herunter. Der fällige Protest erfolgte auf der unteren Ebene der drei westlichen Botschafter in der Bundesrepublik. ${ }^{23}$ Ihr sowjetischer Kollege in OstBerlin entgegnete, der westliche Einspruch müsse als Versuch angesehen werden, die Rechte seines Landes zu beschneiden. Die sowjetischen Flugzeuge hätten unstrittig das Recht, frei und zu jeder Zeit in den „noch bestehenden“ Luftkorridoren zu fliegen. Sie gehörten zu den Streitkräften, die aufgrund eines Vertrages zeitweilig in der DDR stationiert seien und daher dort überall den Luftraum nutzen könnten. Die Feststellung, die Sicherheit der westlichen Militärtransportflugzeuge werde nicht gefährdet, ließ den prinzipiellen Standpunkt erkennen, daß man über die Zivilflüge gar nicht zu sprechen brauche, weil es dafür keine Rechtsgrundlage gebe. Zudem wurde daraus, daß der sowjetische Vertreter in der Luftsicherheitszentrale militärische Flugbewegungen angekündigt und vor einer Benutzung der Luftkorridore zu den genannten Zeiten gewarnt hatte, die Schlußfolgerung abgeleitet, daß sich die dann trotzdem gestarteten westlichen Flugzeuge etwaigen Schaden selbst zuzuschreiben hätten. Der Hinweis, nach völkerrechtlicher Norm seien die Behörden des Staates zu informieren, dessen Gebiet überflogen werde, deutete den Standpunkt an, daß man sich wegen der Flüge eigentlich mit der DDR in Verbindung setzen müsse. ${ }^{24}$ Diesen Anspruch auf Kontrolle erhob Ulbrichts außenpolitischer Mitarbeiter Otto Winzer am 29. Januar ausdrücklich in der Öffentlichkeit. ${ }^{25}$

20 M. Pervuchin an A. A. Gromyko, 10. 2. 1962, AVPRF, 0742, 7, 21, 5, Bl. 35-37; R. Malinovskij/M. Zacharov an das ZK der KPdSU, 17. 2. 1962, RGANI, 5, 30, 399 (rolik 95), Bl. 57; John C. Ausland, Kennedy, Khrushchev, and the Berlin-Cuba Crisis 1961-1964, Oslo 1996, S. 49.

21 Ebd.

22 Telegram From the Embassy in Germany to the Department of State, 8. 2. 1962, in: FRUS 19611963, XIV, S. $796 f$.

23 Schreiben vom 13. 2. 1962 (Anlage zum Schreiben von M. Pervuchin an A. A. Gromyko, 15.2. 1962, AVPRF, 0742, 7, 21, 5, Bl. 64f.).

24 M. Pervuchin an A. A. Gromyko, 15. 2. 1962, AVPRF, 0742, 7, 21, 5, B1. 62 f.

25 Interview des Stellvertretenden DDR-Außenministers Winzer für die Nachrichtenagentur ADN, 
Unbeirrt vom Protest der westlichen Stadtkommandanten, wiederholte die sowjetische Seite die Aktion gegen den Verkehr in den Luftkorridoren. Sie kündigte für den 14. Februar weitere „Übungsflüge“ an, über deren Ablauf sie jede Information verweigerte, und gefährdete durch nahe heranfliegende Miltärmaschinen und Störung des Radarleitsystems mehrere Flugzeuge, darunter eines, in dem der britische Botschafter in Bonn saß.26 Auch nach diesem Vorfall schaltete sich Präsident Kennedy nicht ein. In seinem Schreiben an Chruschtschow vom 15. Februar blieben die Attacken unerwähnt. ${ }^{27}$ Die Westmächte sahen sich aber jetzt zum Protest auf Regierungsebene veranlaßt.28 Aus Moskau erwiderte man, es sei „unverständlich“, was sie dazu veranlaßt habe. Die westlichen Behörden könnten in keiner Weise sowjetische Flüge über DDR-Territorium regeln, die in Übereinstimmung mit den Abkommen zwischen UdSSR und DDR erfolgten. Der Kreml stellte den „,uneingeschränkten“ Zugang“ nach West-Berlin auf dem Luftwege in Abrede und warnte, die Westmächte trügen die „volle Verantwortung für eventuelle unliebsame Folgen“, wenn sie die sowjetischen Mitteilungen nicht beachteten. ${ }^{29}$

\section{Überlegungen und Gespräche über die Attacken gegen den westlichen Flugverkehr}

Der Oberbefehlshaber der sowjetischen Truppen in Deutschland setzte die Aktion fort und gefährdete so weiter den Flugverkehr. ${ }^{30}$ Die Piloten und Passagiere der westlichen Maschinen ließen sich jedoch nicht von der Benutzung der Luftkorridore abschrecken. Chruschtschow äußerte sich gegenüber Ulbricht befriedigt darüber, daß er den Flugverkehr der USA stören und so die „imperialistischen Kräfte“ zwingen konnte, sich zu verteidigen. ${ }^{31}$ Am 6. März betonte Gromyko gegenüber Botschafter Thompson, die Spannungen an den Verkehrstrassen „im Luftraum der DDR“ würden nicht von der UdSSR, sondern von den Westmächten verursacht. Er drohte erneut den Abschluß des Separatvertrags mit der DDR an, wenn sich die westliche Seite nicht zu einer Übereinkunft verstehe, und

29. 1. 1962, in: Dokumente zur Deutschlandpolitik, hrsg. vom Bundesministerium für Innerdeutsche Beziehungen, IV. Reihe, Bd. 8, 1. Hbbd., Frankfurt/Main 1977, S. 105-108.

26 J.C. Ausland, a.a.O., S. 49 f. Vgl. R. Malinovskij/M. Zacharov an das ZK der KPdSU, 17. 2. 1962, RGANI, 5, 30, 399 (rolik 95), Bl. 58.

27 J. F. Kennedy an N. S. Chruščëv, 15. 2. 1962, in: FRUS 1961-1963, XIV, S. 619-622.

28 Aide-mémoire der drei westlichen Regierungen an die Regierung der UdSSR, 15.2. 1962, in: Dokumente zur Deutschlandpolitik, a.a.O., IV, 8/2, S. $153 \mathrm{f}$.

29 Aus dem Aide-mémoire der Regierung der UdSSR an die drei westlichen Regierungen, 17. 2. 1962, ebd., S. $158 \mathrm{f}$.

30 R. Malinovskij/M. Zacharov an das ZK der KPdSU, 24.2. 1962, RGANI, 5, 30, 399 (rolik 95), Bl. 61 f.; R. Malinovskij an das ZK der KPdSU, 3. 3. 1962, RGANI, 5, 30, 399 (rolik 95), Bl. 64f.; R. Malinovskij/M. Zacharov an das ZK der KPdSU, 10.3. 1962, RGANI, 5, 30, 399 (rolik 95), Bl. 68 f.; A. Grečko/M. Zacharov an das ZK der KPdSU. 17. 3. 1962, RGANI, 5, 30, 399 (rolik 95), Bl. $76 f$. Die Angabe von Rolf Steininger, Der Mauerbau. Die Westmächte und Adenauer in der Berlinkrise 1958-1963, München 2001, S. 339, die Störungen seien schon am 22. 2.1962 eingestellt worden, beruht auf der Mißdeutung einer kurzzeitigen Unterbrechung als dauerhaften Abbruch.

31 Vermerk über Besprechung Chruščëv - Ulbricht in Moskau am 26. 2. 1962, 7. 3. 1962, PA-MfAA, G-A 478, Bl. $47 \mathrm{f}$. 
forderte Achtung vor der Souveränität der DDR, die keine „Phrase“, sondern eine „wichtige Bedingung“ sei. Jede Vereinbarung über den Zugang nach West-Berlin zu Land, zu Wasser und in der Luft müsse damit in Einklang stehen. Das war nach Darstellung des sowjetischen Chefdiplomaten für den Westen annehmbar, denn man konnte damit angeblich ohne Schwierigkeit „uneingeschränkten Zugang“ verbinden. ${ }^{32}$

Ulbricht sah im Vorgehen gegen die Luftkorridore die Chance, daß die UdSSR wenigstens einen Teil der gegebenen Zusagen wahrmachte. Wie Chruschtschow ging er davon aus, das Ergebnis der sowjetisch-amerikanischen Gespräche biete keinen Ansatz zur Lösung der Probleme. Die USA hätten ihre Forderungen sogar erhöht. Kennedy mache, was Adenauer vorgeschlagen habe, nur auf geschicktere Weise. Damit verband der SED-Chef Kritik an der sowjetischen Verhandlungsführung. „Wir haben bisher zu einer Reihe von Fragen geschwiegen, weil wir nicht in den Verdacht kommen wollen, daß wir die Gespräche, die auf höchster Ebene geführt werden, stören wollen." Er sprach sich zwar für die Fortführung des Dialogs aus, regte jedoch an zu überlegen, ob nicht für Ende des Sommers der Abschluß eines Friedensvertrags unter Beteiligung der Westmächte ins Auge zu fassen sei. Das wäre zwar ein „schlechter Friedensvertrag“, der allein die Fragen der Grenze und der Hauptstadt regele, die „Überreste des Krieges“ nur teilweise beseitige, die Frage des Luftverkehrs offen lasse und den sonstigen Transit nicht verändere, doch würde er zur „Festigung der DDR“ führen.

Ulbricht suchte Chruschtschow von den Vorzügen zu überzeugen, die bei allen Nachteilen mit dem Abschluß des Friedensvertrages auf dieser Grundlage verbunden seien. Dann hätten die USA „keinen Anlaß zur Verschärfung der Lage“. Man selbst könne die Taktik fortsetzen, „Westberlin als Druckmittel zu benutzen“. In einem beigefügten Protokoll lasse sich festhalten, worüber Einvernehmen bestehe und was „noch offen“ sei. Der SED-Chef machte geltend, die vorgeschlagene Regelung wäre auch im Blick auf die Wahlen zur Volkskammer „zweckmäßig“. Wenn der Friedensvertrag immer nur propagiert werde, akzeptiere das die Bevölkerung nicht. Chruschtschow war anderer Ansicht. „Man muß doch sehen, wie es ist. Wir stören den USA-Flugverkehr. Sie müssen sich verteidigen.“ Mit dem bisher Erreichten könne man vorerst zufrieden sein. „Man muß sehen, daß Westberlin nicht in den Händen Adenauers ist. Am 13. August haben wir maximal erhalten, was möglich ist." Ein Friedensvertrag mit der DDR führe zwar nicht zum Krieg, lasse aber - vor allem von Adenauers Seite - einen wirtschaftlichen Boykott erwarten. Dann müsse die Sowjetunion den Vertrag mit ökonomischen Leistungen bezahlen, die der DDR gewährt werden müßten. Der Kremlchef machte geltend, daß dies nicht im Interesse der UdSSR und des sozialistischen Lagers liege. Im übrigen hielt er es nicht einmal für völlig sicher, daß sich der Krieg vermeiden lasse. ${ }^{33}$

32 Telegram From the Embassy in the Soviet Union to the Department of State, 6. 3. 1962, in: FRUS 1961-1963, XIV, S. 859-862.

33 Vermerk Dölling über Gespräch Chruščëv - Ulbricht am 26. 2. 1962, 7. 3. 1962, PA-MfAA, G-A 478, Bl. 47-49. 
Die Westmächte drangen weiter auf Einstellung der Aktion. Gestützt auf ein amerikanisches Papier mit Auflistung aller Vorfälle, ${ }^{34}$ stellten die Außenminister der USA und Großbritanniens am 11. März Gromyko nachdrücklich die Gefahren für die Sicherheit der Flüge vor Augen, die das sowjetische Vorgehen heraufbeschwöre. Rusk erklärte, das könne nicht geduldet werden. Die USA würden alle erforderlichen Maßnahmen treffen, um die Sicherheit der Flüge zu gewährleisten, und sich durch die Gefahr nicht davon abschrecken lassen, den Luftverkehr nach West-Berlin fortzusetzen. Lord Home ergänzte, das Verhalten stehe in Widerspruch zu dem sowjetischen Anspruch, die Spannung zu mindern. Gromyko bestand darauf, daß die UdSSR das Recht zur Benutzung der Luftkorridore habe und mit der Aktion legitime Interessen der DDR verteidige. Den Vorwurf, sowjetische Militärmaschinen gefährdeten Menschenleben, stellte er in Abrede, indem er die Attacken „nicht identifizierten Bombern“ zuschrieb, deren Verhalten man seinem Land nicht anlasten dürfe. Im übrigen beteuerte er den Willen zur Entspannung. ${ }^{35}$

Am 10. März betonte Chruschtschow gegenüber Kennedy erneut den Verhandlungswillen der UdSSR und legte ihm ein Angebot vor. Darin wurden allen Forderungen aufrechterhalten, aber eine Zugangsbehörde aus Vertretern der Westmächte, der Sowjetunion und anderer Länder für annehmbar erklärt. Diese dürfe aber keine administrative Autorität oder regelsetzende Gewalt bezüglich der Verkehrswege erhalten, denn diese sei eine Prärogative der DDR. Der Kremlchef erneuerte auch den Vorschlag, statt der westlichen Garnisonen könne es einige Jahre lang Truppen der Vier Mächte, der UNO oder neutraler Länder in West-Berlin geben. ${ }^{36}$ In einem „Pravda“-Artikel vom 9. März ${ }^{37}$ und in folgenden Gesprächen Gromykos ${ }^{38}$ kam Interesse an der Fortführung des Dialogs mit Washington zum Ausdruck. In folgenden Gesprächen zeigten jedoch weder der sowjetische Außenminister noch sein Stellvertreter Semjonow Entgegenkommen, wie Rusk mit Enttäuschung feststellte. ${ }^{39}$

Die fortgesetzt ablehnende Haltung der USA gegenüber dem Angebot der Zugangsbehörde rief im Kreml Besorgnis hervor. Würden sie sich auf den Standpunkt stellen, weitere Gespräche seien nutzlos? Das sollte vermieden werden, ohne daß man deswegen Abstriche von den Forderungen ins Auge faßte. ${ }^{40}$ Der Gegensatz verringerte sich nicht. Die sowjetische Seite bestand eisern auf dem Ende des Besatzungsregimes und dem Abzug der westlichen Truppen. Die Zu-

34 Berlin Air Corridors (Anlage zu einer Aufzeichnung über das Gespräch zwischen Rusk und Lord Home am 11. 3. 1962), in: FRUS 1961-1963, XV, S. 20-22.

35 Memorandum of Conversation, 11. 3. 1962, in: FRUS 1961-1963, XV, S. 22-25.

36 N. S. Chruščëv an J. F. Kennedy, 10. 3. 1962, in: FRUS 1961-1963, XV, S. 7-15.

37 Wiedergabe in deutscher Übersetzung in: Dokumente zur Deutschlandpolitik, IV, 8/2, S. 227 f.

38 Memorandum of Conversation [Rusk - Gromyko], 12.3. 1962, in: FRUS 1961-1963, XV, S. 2633; Memorandum of Conversation [Rusk - Gromyko], 13. 3. 1962, ebd., S. 35-39.

39 Memorandum of Conversation [Kohler/Thompson/Bohlen - Semënov/Kovalëv/Suslov], 18.3. 1962, ebd., S. 46-48; Telegram From Secretary of State Rusk to the Department of State [Urteil über sowjetisches Vorschlagspapier], 19.3. 1962, ebd., S. 48-50; Memorandum of Conversation [Rusk - Gromyko], 20. 3. 1962, ebd., S. 51-60; Memorandum of Conversation [Rusk - Gromyko], 22. 3. 1962, ebd., S. 61-69.

40 Telegram From Secretary of State Rusk to the Department of State [Unterredung mit Gromyko], 23. 3. 1962, ebd., S. 72 f. 
gangsbehörde sollte einstimmig entscheiden, also dem Veto ihrer östlichen Mitglieder unterliegen, nur eine bestimmte Zeit lang bestehen und keine administrativen oder territorialen Kompetenzen erhalten. Diese stünden allein der DDR zu. Sonst ergäbe sich eine unzulässige Einmischung in deren innere Angelegenheiten. Die ostdeutsche Souveränität sei absolut zu achten. Semjonow stellte sich gar auf den - bis dahin nicht vertretenen - Standpunkt, daß die angebotene internationale Überwachung des Zugangs nur dann in Betracht komme, wenn sich die Westmächte am Friedensvertrag nicht nur mit Westdeutschland, sondern mit beiden Staaten beteiligten. ${ }^{41}$ Rusk zog Ende März den Schluß, daß sich die Vorschläge der UdSSR seit dem Wiener Treffen vom Juni 1961 nicht wesentlich verändert hätten. 42

Wie es scheint, wollte der Kreml einen Abbruch der Gespräche durch die USA vermeiden. Das ließ sich vermutlich am besten dadurch erreichen, daß die UdSSR die erfolglosen Attacken gegen westlichen Flugverkehr abbrach und damit in Washington die Hoffnung auf positive Ergebnisse neu belebte. Ein derartiges Signal schien geeignet, Aufmerksamkeit in den westlichen Hauptstädten zu erregen, war doch der Luftweg nach West-Berlin von zentraler Bedeutung. Nur er gewährte völlig unkontrollierten und unbehinderten Zugang, während es auf dem Landweg wiederholt immer wieder und mit steigender Tendenz zu Schikanen, Repressalien und Willkürakten kam. ${ }^{43}$ Zudem dürfte das überaus negative Echo der internationalen Öffentlichkeit auf die Attacken gegen die westlichen Luftkorridore dem sowjetischen Führer ein Einlenken nahegelegt haben. Es war nicht gelungen, den westlichen Flugverkehr ernstlich zu stören oder gar einzuschränken. Zugleich machten die zahlreichen Berichte in den westlichen Medien die östliche These unglaubwürdig, die UdSSR setze sich für die internationale Entspannung ein. Auf den psychologischen Schaden hatte Ulbricht in Moskau schon am 27. Februar vorsichtig hingewiesen. ${ }^{44}$ Die sowjetischen Streitkräfte stellten ihre „Flugübungen“ am 30. März 1962 unvermittelt ein. ${ }^{45}$ Außenminister Rusk würdigte das Mitte April bei Wiederaufnahme der Gespräche als Zeichen guten Willens. ${ }^{46}$

41 Gespräch V. S. Semënov - F. Kohler/Ch. Bohlen, 23. 3. 1962, AVPRF, 0129, 46, 346, 12, Bl. 57-67; Gespräch V. S. Semënov - F. Kohler/Ch. Bohlen, 25. 3. 1962, AVPRF, 0129, 46, 346, 12, Bl. 68-76; Gespräch V. S. Semënov - F. Kohler/Ch. Bohlen/L. Thompson, 26. 3. 1962, AVPRF, 0129, 46, 346, 12, Bl. 78-82; Sowjetische Aufzeichnung über die Genfer Gespräche Gromykos mit Rusk im März 1962 (russ.), ohne Überschrift und Datum, AAN, KC PZPR XI A/81, Bl. 394-397; Memorandum of Conversation [Rusk - Gromyko], 26.3. 1962, in: FRUS 1961-1963, XV, S. 76-89; [Klaus] Schütz, Schlußbericht über die anläßlich der Genfer Außenministerkonferenz vom 12. bis 27. März geführten Berlin-Gespräche, o.D. [April 1962], LArchB, B Rep. 002 Nr. 7993b, Bl. 527546.

42 Telegram From Secretary of State Rusk to the Department of State, 26. 3. 1962, in: FRUS 19611963, XV, S. $91 \mathrm{f}$.

43 Von 1952 bis 1961 waren nach Feststellungen des Bundesministeriums für Gesamtdeutsche Fragen etwa ca. 500 Personen für kürzere oder längere Zeit in Haft genommen worden, davon ca. 170 im Jahre 1961, in den ersten vier Monaten 1962 mehr als 100 Personen (Vopo-Willkür auf Interzonenstraßen, in: Telegraf, 20. 5. 1962).

44 Botschafter Dölling, Vermerk über die Besprechung am 27. 2. 1962 beim Genossen Ulbricht [mit Semënov, Il'ičëv und Kabin als sowjetischen Teilnehmern], PA-MfAA, G-A 478, Bl. 55 f.

45 J. C. Ausland, a.a.O., S. 50f. R. Malinovskij/M. Zacharov an ZK der KPdSU, 24. 3. 1962, RGANI, 5, 30, 399 (rolik 95), Bl. 76 f.; R. Malinovskij/M. Zacharov an ZK der KPdSU. 31. 3. 1962, RGANI, 5, 30, 399 (rolik 95), Bl. 81, erwecken den Eindruck, als hätten die Behinderungen schon am 23.3. 1962 aufgehört. Christof Münger, Kennedy, die Berliner Mauer und die Kubakrise, Paderborn 2003, S. 145-152, glaubt, Chruščëv habe die Aktion nach Bekundung neuen Verhandlungs- und 


\section{Differenzen mit Ulbricht}

Ulbricht begrüßte zwar die kompromißlose Haltung, war aber nicht damit einverstanden, daß dies zugleich den Verzicht auf baldigen Abschluß des Friedensvertrages bedeutete. Die DDR durfte nach seiner Ansicht nicht auf unbestimmte Dauer besatzungsrechtlichen Auflagen unterliegen. Er machte bei Perwuchin geltend, die Verzögerung wirke sich negativ auf Stimmung und Haltung der DDRBevölkerung aus. Alle hätten nach dem 13. August den Friedensvertrag erwartet und gedacht, die Schließung der Sektorengrenze werde dessen Abschluß beschleunigen und Bonn zur faktischen Anerkennung der DDR zwingen. Der seither eingetretene Aufschub habe die Lage kompliziert. Es sei schwerer geworden, glaubhaft zu machen, daß die deutsche Frage künftig durch Beseitigung des westlichen Systems gelöst werde.

Den Einwand des Botschafters, die DDR sei in Berlin nach Schließung der Sektorengrenze in einer günstigeren Position als die Bundesrepublik und könne daher zufrieden sein, akzeptierte Ulbricht nicht. Es sei ein Unterschied, ob man vor oder nach Abschluß des Friedensvertrags zur deutschen Frage Stellung nehme. Sei der Vertrag erst einmal unterschrieben, könne man den Menschen in Deutschland mit größerer Überzeugungskraft darlegen, daß Bonn am Ausbleiben der Einheit schuld sei. Lasse dagegen der Friedensvertrag weiter auf sich warten, lasse sich die Position der DDR weit schwieriger begründen. Es seien noch viele Deutsche der Ansicht, daß es bei einer Vereinigung zu einer Synthese von Kapitalismus und Sozialismus kommen werde. Die SED bestehe aber darauf, daß die Einheit nur durch „Liquidierung des Imperialismus in der BRD“ möglich sei und daß bis dahin noch viel Zeit vergehen werde. Ulbricht wies auch die Ansicht zurück, der gemeinsame Kampf seit 1958 habe der DDR doch schon viel Positives gebracht. Das sei zwar nicht zu leugnen, genüge jedoch nicht, um die Westdeutschen von den Vorteilen des Sozialismus und von dessen künftigem Sieg zu überzeugen. ${ }^{47}$

Als Ulbricht damit nicht durchdrang, wandte er sich Teilfragen zu. Am 16. Februar beschwerte er sich bei Chruschtschow, einige Vorgänge gäben der „verleumderische[n] Kampagne“ des Westens Nahrung, daß „die DDR angeblich keine Souveränität besitze“. Das sowjetische Oberkommando habe die SchlieBung der westlichen Luftkorridore für einige Stunden verfügt, ohne die ostdeutschen Behörden zu informieren. Dadurch hätten diese keine Möglichkeit zu Erläuterungen in der Presse gehabt. Als weitere Mißachtung der DDR-Rechte hob er hervor, daß die UdSSR bei einem Agentenaustausch mit den USA an der Grenze zu West-Berlin keinen Offizier der Grenzpolizei hinzugezogen und zudem versäumt habe, die DDR-Regierung über die Berlin-Verhandlungen mit den Amerikanern zu unterrichten. Dagegen sei Bonn von Washington informiert worden, so daß sich die westdeutschen Zeitungen dazu hätten äußern können. Wenn sich die UdSSR zu einseitigem Vorgehen ohne Abstimmung mit der DDR ent-

Konzessionswillens durch Kennedy eingestellt. Der Gang der Geschehnisse gibt darauf keinen Hinweis.

46 Memorandum of Conversation [Rusk - Dobrynin], 16. 4. 1962, ebd., S. 118.

47 Gespräch Pervuchin/Il'ičëv - Ulbricht am 9. 1. 1962, 11. 1. 1962, RGANI, 5, 49, 480 (rolik 9017), B1. 9-12. 
schließe, stelle sich die Frage, warum diese dann nicht ihrerseits etwa die Nachrichtenkabel der USA über DDR-Gebiet durchtrennen oder den amerikanischen Bediensteten völlig den Zutritt zur Hauptstadt der DDR verwehren dürfe.48

Die sowjetische Weigerung, den separaten Friedensvertrag mit der DDR abzuschließen, war auch dadurch bedingt, daß diese wegen ihrer schlechten Wirtschaftslage nicht konfrontationsfähig war. Die ständigen Ersuchen um materielle Hilfe, die Ulbricht deswegen an Moskau richtete, stießen dort zunehmend auf Ablehnung. Seinem Argument, nur bei vermehrter Unterstützung könne er die Abhängigkeit von westdeutschen Lieferungen überwinden, wurde entgegengehalten, er solle die Umstellung auf den RGW-Wirtschaftsraum stärker vorantreiben. ${ }^{49}$ Anfang Februar suchte der SED-Chef mit genauen Angaben und der hinzugefügten Begründung, die Ökonomie sei die „Hauptform des Kampfes“ mit der Bundesrepublik, seine Wünsche nochmals durchzusetzen. ${ }^{50}$ Die sowjetische Führung wollte sich aber keine neuen Lasten aufbürden.

Anfang Juni 1962 machte Chruschtschow gegenüber dem Prager Parteichef Novotný seinem Ärger Luft. Ulbricht halte ihm das Ausbleiben des Friedensvertrages vor. Schließe man diesen ab, wäre mit einer Wirtschaftsblockade des Westens zu rechnen. Dann werde er wieder kommen und von der UdSSR Unterstützung fordern. Das kenne man schon seit langem. Immer komme er und verlange Hilfe. Das gehe zu weit. Die Deutschen hätten Krieg gegen die UdSSR geführt und hätten einen höheren Lebensstandard, aber man solle ihnen immer nur geben und geben. Sie müßten endlich selbst Hand anlegen, um etwas zu erreichen. Die DDR habe große Reserven, doch sei ihre Produktivität gering. Zudem tue Ulbricht bei seinen Hilfsersuchen so, als ob er der Sowjetunion mit dem Sozialismus eine Gnade erweise. Seine Auffassungen gäben zu Sorge Anlaß. Daher habe er sich in Gesprächen mit ihm wiederholt zu Kritik genötigt gesehen. ${ }^{51}$ Trotzdem sah sich der Kreml durch die „relativ schwierige ökonomische Lage“ der DDR zu "großzügige[r] Wirtschaftshilfe“ mittels Warenkrediten und Getreidelieferungen veranlaßt. Die Probleme wurden zwar teilweise auf „objektive Ursachen“ - auf die staatliche Teilung Deutschlands und die schlechte Ernte von 1961 - zurückgeführt, doch schienen die ökonomischen Defizite auch an Planungs- und Leitungsmängeln zu liegen. Auf eine „wesentliche Verbesserung“ der Situation hoffte die sowjetische Seite erst nach zwei bis drei Jahren. ${ }^{52}$

48 Zitiert bei A. M. Filitov, SSSR i „novaja vostočnaja politika“ FRG, in: Cholodnaja vojna i politika razrjadki: diskussionnye problemy, hrsg. vom Institut vseobščej istorii RAN, Bd. 1, Moskau 2003, S. 169-171.

49 Zapis' besedy M. G. Pervuchina i I. I. Il'ičëva s Ul’brichtom, 11. 1. 1962, RGANI, 5, 49, 480 (rolik 9017), Bl. 12-14.

50 W. Ulbricht an N. S. Chruščëv (mit Anlage), 8. 2. 1962, SAPMO-BArch, DY 30/3510, B1. 194f., 198-219.

51 Auszug aus einer tschechoslowakischen Aufzeichnung über ein Gespräch zwischen N. S. Chruščëv und A. Novotný am 8. 6. 1962, in: M. Reiman/P. Luňák, a.a.O., S. 360 f.

52 Botschafter Pervuchin im Gespräch mit seinem ungarischen Amtskollegen: József Kárpáti an Antal Apro/Dezsö Nemes/Imre Hollai/János Szita (ungar.), 29. 9. 1962, MOL 288.f. 32/1962/11ö.e., Bl. 216. 


\section{Die Zutrittsfrage im Beziehungsdreieck mit den USA und der DDR}

Im November 1961 hatte Ulbricht in Moskau darauf gedrungen, wenigstens das „Vorfeld“ des Friedensvertrages durch geeignete Maßnahmen zu „bereinigen“. Es sei „notwendig, als nächsten Schritt eine Ordnung an der Grenze der Hauptstadt der DDR nach Westberlin zu schaffen, um jedwede Verletzung der Souveränität der DDR zu unterbinden." Die sowjetische Forderung an die Westmächte, diese zu respektieren, mache die Einführung der Ausweispflicht für alle Militär- und Zivilpersonen der drei westlichen Staaten beim Betreten Ost-Berlins erforderlich. Sollte sich die andere Seite weigern, die Regelung anzunehmen, müsse ihr die Sektorengrenze verschlossen werden, bis in Regierungsverhandlungen eine Einigung erzielt sei. Die Bürger West-Berlins könnten den für sie vorgesehenen Übergang benutzen, sofern sie eine Genehmigung des Volkspolizeipräsidiums hätten (wofür jedoch die Ausgabestellen noch fehlten). Der SED-Chef sah voraus, daß die Westmächte im Gegenzug die sowjetischen Rechte im Westteil der Stadt in Frage stellen würden, meinte aber, die UdSSR könne unschwer auf die Bewachung des Ehrenmals im Tiergarten und die Beteiligung am Kriegsverbrechergefängnis in Spandau verzichten. Weiter verlangte er die Gleichstellung der Volkskammermitglieder aus Ost-Berlin mit den anderen Abgeordneten, um den Status der Stadt als integralen Bestandteil der DDR zu bekräftigen. ${ }^{53}$

In der Meinung, Präsident Kennedy habe Clays Vorgehen am Checkpoint Charlie mißbilligt und den General nur mit Rücksicht auf Bürgermeister Brandt auf seinem Posten belassen, ${ }^{54}$ räumte der Kreml Ulbricht größeren Handlungsspielraum in der Frage des westlichen Zutritts zu Ost-Berlin ein. Er erhob keinen Einspruch, als der SED-Chef die Absicht äußerte, sich auf das „souveräne Recht der DDR zur Kontrolle des Verkehrs an der Staatsgrenze zu Westberlin“ zu berufen. ${ }^{55}$ Daher forderte die ostdeutsche Polizei ab Spätherbst 1961 von den westlichen Zivilbeamten erneut das Vorzeigen der Ausweise. Das widersprach der Ansicht der USA, ihre Bediensteten seien wegen des Vier-Mächte-Status von (Gesamt-)Berlin berechtigt, sich im Ostsektor ohne Prüfung zu bewegen. Der amerikanische Stadtkommandant, Generalmajor Watson, lehnte es auf einer Fahrt zu seinem sowjetischen Kollegen am 23. Dezember ab, daß seine zivilen Begleiter ihre Identität nachweisen sollten. Daraufhin wurde ihm von der DDR-Grenzpolizei die Durchfahrt verweigert. Er richtete eine Beschwerde an den sowjetischen

53 W. Ulbricht an N. S. Chruščëv, 30. 10. 1961, SAPMO-BArch, NY 4182/1206, B1. 33, 36-38. Ulbricht stützte sich auf eine Ausarbeitung, welche die Sonderstellung Ost-Berlins näher analysierte und die Wichtigkeit ihrer Aufhebung herausstellte: Vorschläge zur Diskussion über die weitere Taktik der DDR im Kampf um den Friedensvertrag und die Lösung der Westberlin-Frage, o.D. [Oktober 1961], SAPMO-BArch, DY 30/3509, Bl. 151-153.

54 Aktenvermerk Gespräch Krolikowski - Žiljakov in Moskau, 20.1. 1962, PA-MfAA, G-A 478, Bl. 27.

55 Dossier über das Verhältnis des Kommandanten der sowjetischen Garnison in Berlin zum USAKommandanten vom Dezember 1961 bis zur Auflösung der sowjetischen Kommandantur, 26. 9. 1963, PA-MfAA, A 264, B1. 98. 
Stadtkommandanten, Oberst Solowjow; ${ }^{6}$ der Bonner Botschafter Dowling protestierte bei Perwuchin. Zugleich wurde Kritik an der Praxis der DDR-Polizei geübt, den durch Ost-Berlin fahrenden amerikanischen Patrouillen zu folgen. ${ }^{57}$

Die Démarchen blieben ohne Erfolg. Die sowjetische Seite stellte sich auf den Standpunkt, mit der Sache nichts zu tun zu haben. Die Prüfung der Ausweise erfolge gemäß den Gesetzen der DDR. Die Verantwortung liege nicht bei der UdSSR, sondern beim Ministerium des Innern bzw. beim Magistrat in Ost-Berlin. Wenn die USA ihre Haltung nicht änderten, müßten sie die Verantwortung für die Folgen tragen. Die UdSSR werde notfalls auch ihrerseits Maßnahmen zur Sicherung des bestehenden Zustands treffen. ${ }^{58}$ Solowjow wandte sich überdies dagegen, daß sich Watson als Kommandant von Berlin bezeichne. Das sei ein „Versuch, seine Rechte auf ganz Berlin zu bestätigen. "59 Mit der Zurückweisung des Protests machte die sowjetische Seite ihre prinzipielle Unterstützung für die Position der DDR klar, daß sich der Vier-Mächte-Status nicht mehr auf den Ostteil der Stadt erstrecke. Vor der vollen Konsequenz, das Recht der Westmächte auf Zutritt zu Ost-Berlin insgesamt aufzuheben, schreckte der Kreml zurück.

Die Bereitschaft der UdSSR, zum einen den Anspruch der DDR auf Beseitigung des Vier-Mächte-Status ihrer Hauptstadt durch Billigung der Vorzeigepflicht zu unterstützen und zum anderen den genehmigungsfreien Zutritt der westlichen Seite hinzunehmen, entsprach der Absicht, zwar die politische Offensive voranzutreiben, aber keine Risiken einzugehen. Der Kreml erlaubte Ulbricht daher nicht, das westliche Recht auf Zutritt insgesamt aufzuheben. Durch die auf das Vorzeigen der Ausweise beschränkte Forderung wurden die Amerikaner unter den Westmächten isoliert, denn die Briten und Franzosen sahen ihre Rechte nicht bedroht und verweigerten daher den USA in dieser Frage die Solidarität. Ihre Bediensteten zeigten ihre Personaldokumente. Als Watson die Zurückweisung der Proteste durch die UdSSR mit einem Zutrittsverbot für Solowjow zum amerikanischen Sektor beantwortete, schlossen sich die Stadtkommandanten Großbritanniens und Frankreichs nicht an und erklärten, daß sie den Ausgesperrten bei sich einreisen lassen würden. Der Streit war für sie alleinige Sache von USA und Sowjetunion, die sie wenig anging. Sie suchten zu vermitteln und schlugen als Kompromiß vor, Amtspersonen sollten ihre Identität nur nachweisen, wenn sie ohne militärische Begleitung seien. Davon wollte die sowjetische Seite nichts wissen. ${ }^{60}$ Es kam ja nicht auf den Nachweis des offiziellen Status an, der durch die be-

56 Generalmajor Watson an Oberst Solov’ëv (russ. Übers.), 30. 12. 1961, RGANI, 5, 30, 399 (rolik 95), Bl. $14 \mathrm{f}$.

57 Dossier über das Verhältnis des Kommandanten der sowjetischen Garnison in Berlin zum USAKommandanten vom Dezember 1961 bis zur Auflösung der sowjetischen Kommandantur, 26. 9. 1963, PA-MfAA, A 264, Bl. 98; M. Pervuchin an A. A. Gromyko, 27. 12. 1961, AVPRF, 0742, 6, 17, 4, Bl. 143 f.; M. Pervuchin an A. A. Gromyko, 5. 1. 1962, AVPRF, 0742, 7, 21, 5, Bl. 1-3; Editorial Note, in: FRUS 1961-1963, XIV, S. 703.

58 Aktenvermerk Gespräch Krolikowski - Žiljakov in Moskau, 20. 1. 1962, PA-MfAA, G-A 478, B1. 27.

59 M. Pervuchin an A. A. Gromyko, 5. 1. 1962, AVPRF, 0742, 7, 21, 5, B1. 2.

60 Telegram From the Mission in Berlin to the Department of State, 11.1. 1962, in: FRUS 1961-1963, XIV, S. 741; Dossier über das Verhältnis des Kommandanten der sowjetischen Garnison in Berlin zum USA-Kommandanten vom Dezember 1961 bis zur Auflösung der sowjetischen Kommandantur, 26. 9. 1963, PA-MfAA, A 264, Bl. 98-100. 
nutzten Dienstfahrzeuge ohnehin gegeben war, sondern auf die Demonstration des Kontrollanspruchs der DDR.

Die Position der USA wurde weiter dadurch geschwächt, daß auch in Washington die Ansicht verbreitet war, es gehe um eine bloße Abfertigungsformalität, die den Streit nicht lohne. Wichtig sei nur der genehmigungsfreie Zutritt. Die oberste Führung griff daher nicht ein. ${ }^{61}$ Solowjow konnte das gegen ihn verhängte $\mathrm{Zu}$ trittsverbot ungestraft mit der Aussperrung Watsons aus Ost-Berlin beantworten. ${ }^{62}$ Die Tatsache, daß der sowjetische Stadtkommandant das Verbot aussprach, machte freilich klar, daß in dieser Frage nach wie vor die UdSSR das Sagen beanspruchte und die DDR nur das tun konnte, was ihr der Kreml zubilligte. Das zeigte sich erneut, als Ulbricht eine „Prüfung“ des Zutritts der amerikanischen Militärbediensteten insgesamt anregte. Das lehnte der Kreml ab: Bis auf weiteres dürfe an der bestehenden Praxis nichts geändert werden.63 Nach anhaltender wechselseitiger Zutrittsverweigerung schlug Watson vor, den Konflikt zu beenden und die Verbote aufzuheben. Die westlichen Zivilbediensteten sollten die Sektorengrenze ohne Nachweis ihrer persönlichen Identität passieren. Oberst Solowjow erklärte sich zur Wiederzulassung seines Gesprächspartners grundsätzlich bereit. Wenn zunächst das gegen ihn verhängte Verbot widerrufen werde, wolle er sich bei den zuständigen Organen der DDR dafür einsetzen, daß diese den Zutritt wieder gestatteten. Die zivilen Amtspersonen der USA jedoch müßten die von ostdeutscher Seite festgelegte Ordnung beachten und seien daher zur Präsentation ihrer Ausweise verpflichtet. Das gelte für alle, auch für die zivilen Begleiter von Militärpersonen. ${ }^{64}$

Der Oberkommandierende der sowjetischen Truppen setzte Ulbricht im Beisein des Botschafters davon in Kenntnis und betonte, man werde auf der Beachtung der DDR-amtlichen Ordnung durch den amerikanischen Stadtkommandanten und sein Personal bestehen. Das Gespräch solle nicht am sowjetischen Amtssitz in Ost-Berlin, sondern in Potsdam stattfinden, um die fortbestehende Gültigkeit des gegen Watson verhängten Verbots des Zutritts (zum Ostsektor) zu unterstreichen. Ulbricht wandte ein, die Tatsache des Treffens der Stadtkommandanten könnte der Vorstellung des Vier-Mächte-Status Berlins Vorschub leisten, die von der DDR abgelehnt werde. Daraufhin versicherte Perwuchin, die UdSSR erkenne keinen derartigen Status an. Der Oberkommandierende fügte hinzu, man werde diesen Standpunkt auch durch Zurückweisung des zu erwartenden westlichen Protests gegen die Ost-Berliner NVA-Militärparade am 1. Mai deutlich machen. ${ }^{65}$ Wie vorgesehen, fand das Gespräch mit Generalmajor Watson am 17. Mai in Potsdam statt. Oberst Solowjow lehnte weisungsgemäß dessen Forderung nach

61 Dorothee Mußgnug, Alliierte Militärmissionen in Deutschland 1946-1990, Berlin 2001, S. 169.

62 Ebd., Bl. 100.

63 Gespräch V. S. Semënov - W. Ulbricht, 27. 2. 1962, AVPRF, 0742, 7,51, 4, B1. 13; Aufzeichnung über von V. Semënov festgestellte Positionen der UdSSR (Anlage zum Schreiben von O. Winzer an W. Ulbricht, 1. 3. 1962), SAPMO-BArch, DY 30/3511, Bl. 11.

64 Dossier über das Verhältnis des Kommandanten der sowjetischen Garnison in Berlin zum USAKommandanten vom Dezember 1961 bis zur Auflösung der sowjetischen Kommandantur, 26. 9. 1963, PA-MfAA, A 264, Bl. 100.

65 Gespräch M. G. Pervuchin/I. Jakubovskij - W. Ulbricht, 8. 5. 1962, RGANI, 5, 49, 480, Bl. 85 f. 
Abschaffung der Vorzeigepflicht ab. Er könne nicht in die Befugnisse der DDR eingreifen. Es kam zu keiner Einigung. ${ }^{66}$

Der Streit zog Repressalien der amerikanischen Besatzungsbehörden nach sich. Wiederholt wurden Militärfahrzeuge der UdSSR an der Fahrt zum sowjetischen Ehrenmal im Tiergarten gehindert, weil darin Oberst Solowjow oder - mutmaßlich - einer seiner Adjutanten (die in das gegen ihn verhängte Zutrittsverbot einbezogen worden waren) darin saß. Das Ziel befand sich zwar im britischen Sektor, doch führte der Übergang, den die DDR für den Verkehr der Vier Mächte vorgesehen hatte, in amerikanisches Gebiet, von dem aus das Ehrenmal anschließend zu erreichen war. Das Angebot der Briten, die Busse könnten über einen anderen Übergang direkt in ihren Sektor gelangen, lehnte Solowjow mit der Begründung $\mathrm{ab}$, daß dies nach den Bestimmungen der DDR nicht statthaft sei, die er zu respektieren habe. Watson weigerte sich im Sommer, den stellvertretenden Stadtkommandanten der UdSSR zur Übergabe von Protestschreiben zu empfangen. Daraufhin ließ Solowjow eine westliche Einladung zum Gespräch zurückgehen. Mit der Auflösung der sowjetischen Stadtkommandantur am 22. August 1962 unterstrich der Kreml die Absicht, keine sichtbare Vier-Mächte-Ebene zuzulassen. Der Umstand, daß der Oberbefehlshaber der sowjetischen Streitkräfte in Deutschland fortan Ansprechpartner der Westmächte in Berlin-Angelegenheiten war, zeigte freilich, daß diese faktisch weiterhin bestand. Der amerikanische Widerstand gegen die Durchfahrt der sowjetischen Busse zum Ehrenmal im Tiergarten wurde dadurch wirkungslos gemacht, daß sich die DDR mit der Benutzung eines in den britischen Sektor führenden Grenzübergangs einverstanden erklärte. ${ }^{67}$

Watson verlor damit den Hebel, mit dem er Druck auszuüben suchte, und sah sich zugleich in der Verlegenheit, daß er vom Besuch Ost-Berlins ausgeschlossen war. Der Botschafter der USA in Bonn ersuchte daher im Dezember 1963 seinen sowjetischen Amtskollegen in Ost-Berlin um Aufhebung des Verbots. Dieser wurde daraufhin aus Moskau zu der Mitteilung ermächtigt, er werde den DDRBehörden eine entsprechende „Bitte“ unterbreiten, falls die amerikanische Seite die Aussagen vom Dezember 1961 für ungültig erkläre und mit dem Vorzeigen der Ausweise einverstanden sei.68 In Washington nahm man daraufhin den Standpunkt ein, es sei vertretbar, wenn sich zivile Amtspersonen gegenüber der Grenzpolizei der DDR auswiesen, solange diese damit nicht das Recht erhielt, den Zutritt zu gewähren oder zu versagen. Dem Kreml und der SED-Führung aber diente das Vorzeigen der Identifikationspapiere fortan als Beweis dafür, daß in der „Hauptstadt der DDR“ allein deren Behörden zu bestimmen hätten, mithin von einem fortgeltenden Vier-Mächte-Status keine Rede sein könne.

66 S. P. Ivanov, Soderžanie besedy generala Solov'ëva s amerikanskim generalom Uotsonom 17.5. 1962 goda, 19. 5. 1962, RGANI, 5, 30, 399, Bl. 107f.; Dossier über das Verhältnis des Kommandanten der sowjetischen Garnison in Berlin zum USA-Kommandanten vom Dezember 1961 bis zur Auflösung der sowjetischen Kommandantur, 26. 9. 1963, PA-MfAA, A 264, Bl. 100.

67 A. Grečko an das ZK der KPdSU (mit Anlage), 9. 1. 1962, RGANI, 5, 30, 399 (rolik 95), Bl. 18-21; R. Malinovskij/M. Zacharov an das ZK der KPdSU (mit Anlage), 10. 2. 1962, RGANI, 5, 30, 399 (rolik 95), Bl. 51-55; Dossier über das Verhältnis des Kommandanten der sowjetischen Garnison in Berlin zum USA-Kommandanten vom Dezember 1961 bis zur Auflösung der sowjetischen Kommandantur, 26. 9. 1963, PA-MfAA, A 264, Bl. 100-103.

68 V. Kuznecov/R. Malinovskij/S. Birjuzov an das ZK der KPdSU, 19. 12. 1963, AVPRF, 0742, 8, 61, 24, Bl. $86 \mathrm{f}$. 
Entgegen östlichen Interpretationen ${ }^{69}$ war damit jedoch keine generelle Regelungskompetenz der DDR in Ost-Berlin-Angelegenheiten verbunden. Der ostdeutschen Seite war es nach wie vor verwehrt, über den Zutritt westlicher Amtspersonen zu entscheiden. Auch wurden die westlichen Stadtkommandanten nicht zur Aufnahme von Beziehungen und zum Abschluß von Vereinbarungen mit den DDR-Behörden bewogen, wie es nach den amtlichen Erklärungen der Fall hätte sein müssen. Ulbricht war sich darüber im klaren. Er kritisierte intern das Festhalten des Kreml an den Vier-Mächte-Rechten und führte aus, nach Auffassung der DDR bestehe die einzige rechtmäßige Funktion des sowjetischen Botschafters darin, der diplomatische Vertreter seines Landes zu sein. Die ihm übertragenen Kompetenzen als bevollmächtigter Hochkommissar in Deutschland und als Gegenüber der Westmächte in allen Vier-Mächte-Angelegenheiten seien dagegen illegitim. ${ }^{70}$ Damit verband sich unausgesprochen der Vorwurf, die UdSSR befinde sich mit ihrem Vorgehen in Widerspruch zu ihren eigenen Erklärungen gegenüber dem Westen, denen zufolge sie die Existenz eines Vier-Mächte-Status ablehnte.

\section{Fortführung und Stillstand der Gespräche mit den USA}

Die USA eröffneten die neue Gesprächsrunde Anfang April mit einem Papier, in dem sie Prinzipien für eine Berlin-Übereinkunft, Verfahren zu deren Aushandlung und Zwischenschritte auf dem Weg dorthin formulierten. Demnach sollten sich die Seiten von den Grundsätzen leiten lassen, daß West-Berlin seinen eigenen „way of life“ wählen könne, daß seine gesellschaftliche Ordnung von allen Seiten zu respektieren sei, daß seine Lebensfähigkeit aufrechterhalten werden müsse und $\mathrm{daß}$ die uneingeschränkte Verbindung (communication) mit Westdeutschland bei Achtung der „Funktionen, Aktivitäten und Prärogativen der zuständigen Behörden“ gewährleistet werde. Ein Rat der stellvertretenden Außenminister der USA, der UdSSR, Großbritanniens und Frankreichs sollte alle Vorschläge prüfen mit dem Ziel, zu Vereinbarungen zu gelangen, die diese Grundsätze in Übereinstimmung mit den Interessen der beteiligten Länder zur Geltung brächten. Damit sollte die Verpflichtung einhergehen, die Verfahren des Zugangs bis zu der zu treffenden Neuregelung auf dem Stand vom 1. Januar $1962 \mathrm{zu}$ belassen. Zugleich wurden Vereinbarungen mit der Sowjetunion über nukleare Nichtverbreitung und wechselseitigen Angriffsverzicht in Aussicht genommen. ${ }^{71}$

Die amerikanische Hoffnung, der Dialog werde damit auf eine neue Basis gestellt, erfüllte sich nicht. Gromyko hielt in seiner Erwiderung an den Forderungen nach Umwandlung West-Berlins in eine „Freie Stadt“, Beseitigung des westlichen Besatzungsregimes, Regelung des Transits auf der Grundlage uneingeschränkter DDR-Souveränität und Schaffung eines nicht über Vollmachten verfügenden Schlichtungsorgans fest und lehnte alle davon abweichenden Überlegungen kate-

69 Gespräch M. G. Pervuchin - W. Ulbricht, 9. 5. 1962, RGANI, 5, 49, 480 (rolik 9017), Bl. 85-89.

70 Gespräch V. S. Semënov - W. Ulbricht, 27. 2. 1962, AVPRF, 0742, 7,51, 4, Bl. 15.

71 Draft Principles, Procedures, and Interim Steps, 3. 4. 1962, in: FRUS 1961-1963, XV, S. 95-98. 
gorisch ab. ${ }^{72}$ Im Gespräch zwischen Botschafter Dobrynin und Außenminister Rusk am 16. April änderte sich daran nichts. ${ }^{73}$ Acht Tage später formulierte Gromyko auf der Tagung des Obersten Sowjets den gewohnten unnachgiebigen Standpunkt und erklärte, einer Annäherung der Positionen stünden noch viele Hindernisse im Wege. ${ }^{74}$ Trotzdem sah man in Moskau weiteren Gesprächen optimistisch entgegen. Wie ein zuständiger Mitarbeiter des Außenministeriums einem DDR-Vertreter darlegte, waren die USA ernstlich an einer Lösung der West-Berlin-Frage interessiert. Sie hätten begriffen, daß eine Regelung notwendig sei. Wenn es noch nicht so weit sei, so liege das daran, daß sie zuvor noch so viel wie möglich herauszuholen suchten. ${ }^{75}$

Für die sowjetische Hoffnung bot die prinzipielle Einstellung Kennedys eine plausible Grundlage. Der Präsident ging von der Leitidee einer wechselseitigen Achtung des Status quo aus. Zwar bezog sich dieses Prinzip nach Washingtoner Verständnis nicht nur auf territoriale Besitzstände, sondern auch auf rechtliche Ansprüche, was der Kreml nicht gelten ließ. Aber Chruschtschow glaubte angesichts der großen Konzessionsbereitschaft seines Gegenspielers auch diese Hürde überwinden zu können und sah sich in dieser Erwartung dadurch bestärkt, daß Kennedy willens war, die UdSSR für die Ablehnung gestellter Forderungen - vor allem des Verlangens nach Abzug der westlichen Garnisonen und uneingeschränkter Verfügung der DDR über die Zugangswege - durch Zugeständnisse in „breiteren Fragen“ zu entschädigen. Erkannte der Präsident damit nicht bereits die Berechtigung des sowjetischen Verlangens an? Diese Vermutung leuchtete um so mehr ein, als er damit einverstanden war, den Standpunkt aufzugeben, daß die westliche Anwesenheit weiter auf Vier-Mächte-Recht beruhen müsse, und willens war, irgendeine andere Rationale zu akzeptieren. Von dieser war anzunehmen, daß sie kaum eine feste Basis für den Anspruch auf Präsenz bot. Aus sowjetischer Sicht war zudem positiv, daß Kennedy einer Anerkennung der DDR wenig abgeneigt war und damit in Aussicht stellte, den Bonner Anspruch auf Wiedervereinigung in Freiheit nicht mehr zu unterstützen. Eine zentrale Verpflichtung gegenüber der Bundesrepublik in den Verträgen über deren Integration in den Westen erschien dem Präsidenten damit vernachlässigenswert.

Unausweichlich führte das zum Konflikt mit der Bundesregierung. Schon seit langem, vor allem seit Jahreswechsel, hatte sich diese gegen die Absicht gewandt, dem Kreml weit entgegenzukommen. Auch de Gaulle war, wiewohl aus anderen Erwägungen, nicht mit der fortgesetzten Nachgiebigkeit Kennedys einverstanden. Adenauer war überzeugt, West-Berlin sei auf diese Weise längerfristig nicht zu halten, und meinte zudem, die UdSSR werde die Konzessionen ohne Gegenleistung einstreichen und daraufhin noch mehr verlangen. Die Auseinandersetzung mit Kennedy brach offen aus, als dieser die Idee einer internationalen Zugangsbehörde lancierte, die über alle Fragen des Verkehrs zwischen West-Berlin und

72 E. Honecker an W. Ulbricht (Wiedergabe einer sowjetischen Information über Gespräche Gromyko - Rusk), 6. 4. 1962, SAPMO-BArch, DY 30/3291, Bl. 152-156.

73 Memorandum of Conversation, 16. 4. 1962, ebd., S. 114-119.

74 Bericht Gromykos über die Genfer Verhandlungen, 24. 4. 1962, in: Die sowjetische Außenpolitik. Akte und Dokumente des Obersten Sowjets der UdSSR 1956-1962, Moskau 1962, S. 215-248.

75 Nestler, Aktenvermerk über ein Gespräch mit Basmanov (3. Eur. Abt.) am 15. 5. 1962, PA-MfAA, A-617, Bl. 4. 
Westdeutschland zu entscheiden haben würde. Sie sollte aus jeweils einem Vertreter von drei westlichen und östlichen Ländern, beider deutscher Staaten und West- wie Ost-Berlins, dazu dreier Neutraler bestehen. Weiterhin wollte der Präsident die Bildung von drei deutsch-deutschen Ausschüssen akzeptieren.

Adenauer war entsetzt. Der Plan lief nach seiner Einschätzung darauf hinaus, daß der Westen nicht nur einen entscheidenden Schritt zur Anerkennung der DDR tat, sondern auch zur Infragestellung des Rechts auf Zugang nach West-Berlin bereit war. Der Vorschlag mache den Transit von den Voten dreier schwacher Kleinstaaten abhängig, die dem Druck der UdSSR ausgesetzt sein würden. Im Konfliktfall werde diese daher ihren Willen durchsetzen. Der Bundeskanzler sah in dem Projekt nichts als blanke Beschwichtigungspolitik auf Kosten der Deutschen. Die Information über den Plan kam in die Presse. Durch die damit hergestellte Öffentlichkeit wurde das Vorhaben diskreditiert. Ob bzw. inwieweit Adenauer dabei seine Hand im Spiel hatte, wie man in Washington vermutete, ist ungeklärt, doch war das Ergebnis ganz in seinem Sinne. Kennedy war aufgebracht und sprach intern von einem Vertrauensbruch. Bei aller Empörung konnte er sich, da er sich zugleich französischer Ablehnung gegenübersah, aber nicht der Einsicht verschließen, daß der Zusammenhalt des westlichen Bündnisses akut gefährdet war, wenn er an dem Vorschlag festhielt. Die UdSSR lehnte ihn ohnehin ab, so daß es leicht war, ihn fallenzulassen. Das Einvernehmen unter den NATO-Staaten wurde, zumindest nach außen hin, wiederhergestellt. ${ }^{76}$

\section{Krise der amerikanisch-sowjetischen Gespräche}

Die Widerstände in Bonn und Paris bewogen die amerikanische Regierung dazu, eine Pause in ihrer Politik der Angebote einzulegen, um zunächst die Situation im Bündnis zu klären. Rusk gab daher am 27. April gegenüber Dobrynin keinen klaren Standpunkt zu erkennen.77 Die sowjetische Führung erörterte am folgenden Tag den Gesprächsstand und legte „Direktiven für weitere Verhandlungen über die Frage des Abschlusses eines deutschen Friedensvertrages und die Normalisierung der Lage in West-Berlin auf dieser Grundlage“ fest. Danach durfte die Bundesrepublik auf keinen Fall in einer Zugangskommission vertreten sein. Dagegen erschienen westliche Truppen in West-Berlin unter der Flagge der UNO annehmbar. Darüber lasse sich eine Vereinbarung treffen, wenn die Westmächte mit einer zeitlichen Begrenzung ihres Aufenthalts einverstanden seien. Nach sowjetischer Einschätzung mußten sie eigentlich Interesse an einer solchen Regelung haben,

76 Thomas Opelland, Gerhard Schröder (1910-1989), Düsseldorf 2002, S. 449-458; R. Steininger, a.a.O., S. 334-349; Frank A. Mayer, Adenauer und Kennedy: A Study in German-American Relations, 1961-1963, New York 1996, S. 68-73; Hans-Peter Schwarz, Adenauer, Band 2: Der Staatsmann 1949-1967, Stuttgart 1986, S. 743-749; C. Münger, a.a.O., S. 154-161. Dazu aus der Innensicht des Bonner Bundeskanzleramts: Horst Osterheld, „Ich gehe nicht leichten Herzens ...". Adenauers letzte Kanzlerjahre - ein dokumentarischer Bericht, Mainz 1987 (2. Aufl.), S. 85-114, und aus der Perspektive der Botschaft in Washington: Wilhelm G. Grewe, Rückblenden 19761951, Frankfurt/Main 1979, S. 526-535, 545-559.

77 Telegram From the Department of State to the Embassy in Germany, 28. 4. 1962, in: FRUS 19611963, XV, S. $121 \mathrm{f}$. 
weil ihnen eine Entspannung der Lage in Berlin nütze. Die UdSSR ging gleichwohl davon aus, den Druck weiter aufrechterhalten zu können. Man könne auch an eine Vereinbarung über eine verringerte Streitkräftepräsenz denken, an der Dänemark, Norwegen, die Niederlande oder Belgien, Polen und die Tschechoslowakei beteiligt wären. Am besten käme dazu noch ein Abkommen über die Erweiterung des Ost-West-Handels. ${ }^{78}$

Der Beschluß lag auf der am 8. Januar fixierten Linie. Besatzungsregime und Zugangsrecht sollten als die beiden westlichen Kernpositionen beseitigt werden. Die dafür angebotenen Konzessionen waren ohne Substanz und auf kurze Dauer berechnet. Im Endergebnis sollten die Forderungen ohne Einschränkung durchgesetzt werden. Wenn die USA diesen Preis für die Beruhigung des Verhältnisses zur UdSSR nicht zahlen wollten, dann mußte der Druck noch so lange weiter ausgeübt werden, bis sie dazu bereit waren. Als die sowjetische Führng diesen Beschluß faßte, wußte sie noch nicht, daß sich die Bundesrepublik und Frankreich anschickten, Kennedys Verständigungseifer wirksam zu bremsen.

In der ersten Maiwoche erkannte man im Kreml, daß die amerikanische Regierung weniger konziliant wurde. Anfänglich hoffte man, sie durch einen Appell in der „Pravda“ wieder auf den gewünschten Kurs zu bringen. ${ }^{79}$ Man verstand nicht, warum die USA auf einmal Zurückhaltung zeigten, und glaubte, sie durch demonstrative Kompromißlosigkeit und öffentliche Abkanzelung Adenauers zu mehr Entgegenkommen veranlassen zu können. ${ }^{80}$ Das verstärkte die Verhärtung der amerikanischen Haltung zusätzlich. Die sowjetischen Akteure konnten sich nicht vorstellen, daß die Politik der westlichen Führungsmacht von Rücksichten auf Verbündete mitbestimmt wurde, und suchten den Grund in inneren Verhältnissen der USA. Dabei spielte die bisherige Einschätzung, daß Kennedy ein schwacher Mann ohne politische Autorität sei, eine große Rolle. Hatte er die Kontrolle über die Regierung an die „Falken“ verloren? Standen die Zeichen in Washington auf Konfrontation? Chruschtschow war besorgt und suchte nach einer Antwort.

Als Kennedys Pressesekretär, Pierre Salinger, am 11. Mai zufällig nach Moskau kam, erhoffte sich der Kremlchef von ihm Aufschluß und lud ihn deswegen in seine Datscha ein. Wie groß sein Interesse war, zeigte sich daran, daß er sich volle 14 Stunden mit dem noch sehr jungen Mann unterhielt. Er kam dabei augenscheinlich zu dem Schluß, daß er nach wie vor mit Kennedy als entscheidendem Politiker zu rechnen habe. Um sich ihm als Partner zu empfehlen, mit dem zu verhandeln sich lohne, präsentierte sich Chruschtschow als maßvoll-vernünftiger Staatsmann, der nur verärgert darüber sei, wie die Amerikaner mit ihm umsprängen. Der zentrale Streitpunkt sei Berlin. Wenn man dieses Problem löse, lasse sich alles regeln, was UdSSR und USA voneinander trenne. Er ließ erkennen, daß er Verhandlungsfortschritte in anderen Fragen für unwichtig erachtete. Damit war Kennedys Bemühen ohne Chance, sowjetisches Nachgeben in der Berlin-Frage

78 Protokoll der Sitzung des Präsidiums des ZK der KPdSU (TOP I), 28. 4. 1962, in: A. A. Fursenko, Archivy Kremlja, a.a.O., S. $553 \mathrm{f}$.

79 Obozrevatel' [zur Kennzeichnung quasi-amtlicher Stellungnahmen verwendetes Pseudonym], Peregovory, no ne igra v peregovory, in: Pravda, 3. 5. 1962.

80 Protokoll der Sitzung des Präsidiums des ZK der KPdSU (TOP XXXIII), 9. 5. 1962, in: A. A. Fursenko, Archivy Kremlja, a.a.O., S. 554. 
durch Zugeständnisse an anderer Stelle zu erkaufen. Chruschtschow erklärte weiter, er sei wie das amerikanische Volk zutiefst enttäuscht, daß man noch so weit von einer Entspannung entfernt sei. Einer Interviewaussage Kennedys, in der nebenher von der Option des nuklearen Ersteinsatzes die Rede gewesen war, legte er den Sinn bei, der Präsident habe einem Angriff mit Kernwaffen das Wort geredet. Tadelnd meinte er, Eisenhower und Dulles (die ihm als besondere Feinde der UdSSR galten) wären dazu nie bereit gewesen. ${ }^{81}$

Der Kremlchef wollte nicht wahrhaben, daß sich der amerikanische Verhandlungsspielraum entscheidend verengt hatte. Nach wie vor legten er und seine Mitarbeiter dem Widerstand wichtiger NATO-Partner gegen Kennedys Politik nicht die Bedeutung bei, die ihm zukam. Bagatellisierend hieß es, von den westlichen Staaten sei „Westdeutschland in stärkerem, Frankreich in geringerem Maße an einer Übereinkunft desinteressiert“; beide suchten sie daher „um jeden Preis zu verhindern.“ Die USA seien weiter gegangen, als die Berichte in der Presse erkennen ließen, und Großbritannien finde sich zu noch größerem Entgegenkommen bereit. Das entsprach zwar weithin den Realitäten, doch zeigt die daran geknüpfte Erwartung, daß die Amerikaner aus starkem Interesse an weiteren Verhandlungen noch bessere Angebote auf den Tisch legen würden, ein grundlegendes Unverständnis der Lage. Tatsächlich war nicht zu erwarten, daß die Gespräche trotz Bonner und Pariser Widerstrebens in der bisherigen Weise weiterliefen. Vor allem ging die Annahme fehl, daß Ulbrichts Vorschlag einer Zugangsbehörde, die zur Wahrung unumschränkter DDR-Souveränität keinerlei Autorität, sondern bloß die Befugnis zur Regelung technischer Fragen haben sollte, von Washington akzeptiert werden könnte. ${ }^{82}$

Als am 30. Mai auf amerikanische Initiative hin ein neues Gespräch zustande kam, leitete Rusk seine Ausführungen mit der Feststellung ein, Chruschtschow (dem das Entgegenkommen des Präsidenten nicht ausgereicht hatte) habe die $\mathrm{Zu}$ gangsbehörde, die zur Kontroverse im Westen geführt habe, bereits abgelehnt. Damit sei dieser Vorschlag nicht mehr aktuell. In dem Jahr, das seit der Wiener Gipfelbegegnung vergangen sei, habe man zwar wechselseitig die Standpunkte geklärt, aber keinen Fortschritt erzielt. Mit dem Angebot einer Ausweitung der zur Diskussion stehenden Fragen seien die USA der UdSSR entgegengekommen, doch habe diese sich umgekehrt nicht bemüht, vitale amerikanische Interessen zu berücksichtigen. Botschafter Dobrynin erwiderte, diese Darstellung sei nicht neu. Statt ihrer habe er differenzierte Stellungnahmen zu Einzelfragen erwartet. Im weiteren Gespräch bemühten sich beide Unterhändler vergeblich, Gemeinsamkeiten zu finden. ${ }^{83}$

In der nächsten Unterredung am 18. Juni erklärte der sowjetische Unterhändler, neue Instruktionen erhalten zu haben. Seine Regierung habe einem weiteren Gedankenaustausch zugestimmt, der auf eine Vereinbarung abzielen müsse. Damit verband sich jedoch keine flexiblere Haltung. Dobrynin hielt an dem bisheri-

81 Aleksandr Fursenko/Timothy Naftali, „One Hell of a Gamble“. Khrushchev, Castro and Kennedy 1958-1964, New York-London 1997, S. 176 f.

82 Äußerungen von Botschafter Pervuchin im Gespräch mit seinen ungarischen Amtskollegen: István Rostás an Imre Hollai (ungar.), 22. 5. 1962, MOL 288.f. 32/1962/11 ö.e., Bl. 167.

83 Memorandum of Conversation, 30. 5. 1962, in: FRUS 1961-1963, XV, S. 161-172. 
gen Standpunkt uneingeschränkt fest. Demnach sollte es ausschließlich um eine „Normalisierung“ der Situation in West-Berlin durch Abschluß eines Friedensvertrags und Beseitigung der Besatzungsrechte gehen. Der Aufenthalt der westlichen Truppen in der Stadt könne nicht weiter geduldet werden. Gegen die USA richtete sich der Vorwurf, jeden Kompromiß abzulehnen. Sie seien nicht bereit gewesen, eines der Angebote für einen Stationierungsersatz anzunehmen, und hätten auch die Offerte einer Zugangsbehörde abgelehnt. Dieser Vorschlag entsprach nach sowjetischer Darstellung den Interessen beider Seiten, weil sowohl der westliche Wunsch nach internationaler Aufsicht als auch das Erfordernis eines uneingeschränkt-souveränen Verfügungsrechts der DDR über die Verkehrswege auf ihrem Territorium berücksichtigt werde. Eine Übereinkunft wäre jedoch ausgeschlossen, wenn sich die Westmächte den Anspruch Adenauers auf West-Berlin als Land der Bundesrepublik oder dessen Idee eines Zugangsvertrags zu eigen machten. Der sowjetische Botschafter appellierte an den amerikanischen Außenminister, sich bald zur Einigung bereit zu finden. Jede Verzögerung ermutige die westdeutsche Seite zu neuen Provokationen und feindlichen Akten gegen die sozialistischen Länder.

Die Anregung der USA, die teilungsbedingten Probleme in Berlin durch „technische“ Kommissionen zu regeln, veranlaßte Dobrynin zu dem Hinweis, die DDR habe dem West-Berliner Senat ein Abkommen unterbreitet, um nach den vorangegangenen „Verteidigungsmaßnahmen“ - gemeint war die Schließung der Sektorengrenze - „den Verkehr zwischen West-Berlin und der Hauptstadt der DDR zu erleichtern“. Das sei eine „innere Angelegenheit der Deutschen“. Die Formulierungen machten deutlich, daß der Kreml das Thema aus den VierMächte-Erörterungen heraushalten wollte und die vorgeschlagene Vereinbarung als Hebel für ein politisches Arrangement ansah, das der DDR staatliche Anerkennung verschaffen sollte. Rusk erklärte das alles für völlig unannehmbar und sprach von einem „beunruhigenden Mangel“ an Kompromißbereitschaft auf sowjetischer Seite. Alle Angebote, mit denen man der UdSSR entgegengekommen sei und sich bemüht habe, ihr den Gesichtsverlust offenen Abrückens von den gestellten Forderungen zu ersparen, seien abgelehnt worden. Das lasse auf die Absicht schließen, die USA und die anderen Westmächte aus Berlin hinauszuwerfen. Dagegen, so gab er zu verstehen, werde man sich mit allen Mitteln zur Wehr setzen. ${ }^{84}$

Die sowjetische Führung beriet am 1. Juli über das weitere Vorgehen. Sie suchte nach wie vor mit dem dreifachen Vorschlag einer Reduzierung der West-Berliner Garnison, ihrer - diesmal zeitlich gestaffelten - Übernahme durch die Vereinten Nationen und einer Befristung jeder Truppenpräsenz politisches Terrain zu gewinnen. Die unausgesprochene Vorbedingung jeder Regelung war der Verzicht der Westmächte auf das Besatzungsregime. Bei den Gesprächen über die Zugangsfrage sollte die Errichtung eines internationalen Kontrollorgans von vornherein außer Betracht bleiben, weil dieses unannehmbar sei. Als Alternative wurde erwogen, auf die westliche Seite dadurch Druck auszuüben, daß die UdSSR - entweder selbst oder durch neutrale Staaten - die deutsche Frage in der UNO zur Diskus-

84 Memorandum of Conversation, 18. 6. 1962, ebd., S. 177-187. 
sion stellte. Davon versprach sich der Kreml positive Resonanz, die freilich mit einer Verschärfung der Beziehungen zum Westen erkauft werden müsse. ${ }^{85}$

Dobrynin unterbreitete Rusk am 12. Juli einen förmlichen Vorschlag, der die bis dahin gültige Position etwas modifizierte. Für die Truppen der Vereinten Nationen, die nach Aufhebung des Besatzungsregimes während einer Anfangszeit die Unabhängigkeit und Sicherheit West-Berlins garantieren sollten, wurden ein vereinbarter Sonderstatus, die Ausstattung mit Personal aus Staaten außerhalb der beiden Militärgruppierungen und polizeiliche statt militärische Fähigkeiten ins Auge gefaßt. Dazu wurden polizeiliche Militärformationen der UN („UN police military formations“ in der amerikanischen Übersetzung) vorgesehen, die sich jeweils zur Hälfte aus Einheiten der drei Westmächte und von je ein bis zwei kleineren Staaten der NATO und des Warschauer Pakts zusammensetzen sollte. Als Umfang war - gemäß einem kurz zuvor unterbreiteten Vorschlag Chruschtschows an Kennedy ${ }^{86}$ - höchstens an die Stärke der westlichen Garnisonen von zusammen 11000 Mann gedacht mit Verringerungen von jeweils 25\% in den nächsten vier Jahren. Danach sollte es keine Soldaten mehr geben in West-Berlin, dessen staatliche Unabhängigkeit als „Freie Stadt“ durch Garantien der UN geschützt werden würde.

Der „freie Zugang“ war nach sowjetischer Ansicht durch ein Abkommen zu sichern, das „mit der gebotenen Achtung gegenüber der DDR-Souveränität auf der Grundlage der allgemein etablierten internationalen Praxis“ abgeschlossen werden sollte. Im sowjetischen Sprachgebrauch umschrieb dies den Standpunkt, daß die Verfügung der DDR über den Transitverkehr durch nichts beschränkt werden dürfe. Etwa auftretende Streitfragen sollten dem von der UdSSR früher vorgeschlagenen schiedsrichtlichen Gremium überwiesen werden, das, wie deutlich gemacht worden war, nur einstimmig, also im Konsens mit der ostdeutschen Seite, tätig werden konnte. Das sowjetische Angebot war nach Rusks Urteil insgesamt eine bloße Variation der altbekannten Forderungen und damit gänzlich unannehmbar. ${ }^{87}$

\section{Gescheiterte Bemühungen um eine Einigung}

Gromyko zog im Gespräch mit DDR-Vertretern das Fazit, zwar beteuerten die Amerikaner ihren Willen zum Einvernehmen, doch sei „nicht der geringste Fortschritt erreicht worden“. .88 In Moskau hatte man bereits am 12. Juli öffentlich Enttäuschung darüber bekundet, „daß die Regierungen der Westmächte kein Verständnis für die Notwendigkeit zeigen, Auswirkungen des zweiten Weltkriegs durch Unterzeichnung eines deutschen Friedensvertrags zu beseitigen“, und propagandistisch die Schuld daran ihrer „Nachsicht [...] gegenüber jenen westdeut-

85 Protokoll der Sitzung des Präsidiums des ZK der KPdSU (TOP II), 1. 7. 1962, in: A. A. Fursenko, Archivy Kremlja, a.a.O., S. 569.

86 N. S. Chruščëv an J. F. Kennedy, 5. 7. 1962, ebd., S. 207-212.

87 Memorandum of Conversation, 12. 7. 1962, ebd., S. 215-222.

88 Ständiger Vertreter der DDR in Genf, Vermerk über ein Gespräch mit Genossen Gromyko am 24. 7. 1962, 27. 7. 1962, PA-MfAA, G-A 478, Bl. 72 f. 
schen Kreisen“ zugewiesen, „welche die Forderung nach Revanche und nach Revision der Ergebnisse des zweiten Weltkrieges zum Panier ihrer Politik erhoben haben.“ Sonst würden sie gegen den sowjetischen Vorschlag „auf [sic] Umwandlung Westberlins zu einer freien entmilitarisierten Stadt keine Einwände erheben.“ Als Ziel des Friedensvertrages wurde herausgestellt, „die Möglichkeiten der Entfesselung einer Aggression durch den deutschen Imperialismus abzuschnüren. “89 Hoffte Moskau, Druck auf die Westmächte auszuüben, wenn man ihnen vorwarf, sie machten sich zu Komplizen Bonner Friedensfeinde?

Am nächsten Tag setzte Chruschtschow im Gespräch mit Journalisten aus den USA einen anderen Akzent. Er erklärte, die „Schwierigkeiten“ bei der Lösung des Deutschland-Problems ergäben sich aus der „amerikanischen Konzeption des Antikommunismus“. Davon abgesehen, gebe es doch „viel Gemeinsames“ in den Standpunkten beider Seiten, die zur Verständigung führen müßten. Als Kernfrage bezeichnete der sowjetische Führer den Abzug der westlichen Truppen aus WestBerlin und die Beseitigung des von ihnen aufrechterhaltenen Besatzungsregimes in der Stadt. Darüber könne man sich doch einigen, denn weder die Vereinigten Staaten noch Großbritannien und Frankreich brauchten West-Berlin. Trotzdem klammerten sie sich an diesen „Spannungsherd“, der ihnen, so war zu entnehmen, nur Verdruß einbringe. ${ }^{90}$

Der diplomatische Dialog war erneut in der Sackgasse. Während die amerikanischen Militärs Vorbereitungen für eine mögliche Luftbrücke wie 1948/49 trafen, ${ }^{91}$ suchte Präsident Kennedy den Stillstand zu überwinden. Zunächst machte er der sowjetischen Seite mit aller Deutlichkeit klar, wo die Grenzen der Kompromißbereitschaft lagen. Während einer Unterredung erklärte er Dobrynin, die Anwesenheit westlicher Truppen in West-Berlin sei ein vitales Interesse der USA. Daher sei keine Alternativregelung akzeptabel. Diese wäre ein unverhüllter Hinauswurf, den man nicht einmal durch ein Feigenblatt vor der Öffentlichkeit verbergen könnte. Das würde im Westen das Vertrauen auf die Führung der USA zerstören und würde mithin auf einen großen Sieg für die Sowjetunion und eine ebenso große Niederlage für den Westen hinauslaufen. Wie unausgesprochen zum Ausdruck kam, konnte sich sein Land das nicht leisten. Der Botschafter wandte ein, West-Berlin sei eine große Quelle von Konflikten, und die Entfernung der westlichen Truppen von dort würde die Gefahren erheblich verringern. Der Präsident äußerte zwar Verständnis für diese Bedenken, fügte aber hinzu, er könne nur wiederholen, daß für die USA der Abzug der Truppen eine Katastrophe wäre. Dagegen würde deren Verbleiben für die UdSSR keine solche Katastrophe bedeuten. ${ }^{92}$

In einem Schreiben an Chruschtschow suchte Kennedy nach einem Ausgangspunkt für einen erfolgversprechenden Dialog. Er stellte drei denkbare Grundlagen für die Behandlung der strittigen Probleme heraus. Man könne den Zweiten Weltkrieg durch eine Regelung beenden, die auf dem frei geäußerten Willen des

89 TASS-Erklärung (ausdrücklich auf amtlicher Ermächtigung beruhend), 12.7. 1962, in. Dokumente zur Deutschlandpolitik, IV, 8/2, S. 834-837).

90 Gespräch Chruščëvs mit amerikanischen Journalisten, 13. 7. 1962, ebd., S. 843-848.

91 W. Ulbricht an Armeegeneral I. I. Jakubovskij [Übermittlung einer nachrichtendienstlichen Information], 31. 7. 1962, SAPMO-BArch, DY 30/3691, Bl. 136 (dt.), 137 (russ. Übers.).

92 Memorandum of Conversation, 17. 7. 1962, in: FRUS 1961-1963, XV, S. $223 \mathrm{f}$. 
deutschen Volkes beruhe. Alternativ dazu sei eine Vereinbarung möglich, die allein auf eine Verbesserung der Lage in Berlin abziele. Schließlich lasse sich die Lage in Deutschland als ein derzeit nicht zu änderndes Faktum behandeln, das Übereinkünfte nur in anderen Bereichen erlaube. ${ }^{93}$ Die Anregung blieb in Moskau ohne Resonanz. Der Kreml hielt an seinem Standpunkt unverändert fest. Im anschließenden Meinungsaustausch prallten die gegensätzlichen Auffassungen hart aufeinander. ${ }^{94}$

Am 25. Juli stellte der amerikanische Außenminister seinem sowjetischen Amtskollegen zunächst die eher rhetorische Frage, wieso die UdSSR nicht dem Beispiel der Westmächte gegenüber der Bundesrepublik folge und sich ihrerseits gegenüber der DDR die Zuständigkeit für die Probleme Gesamtdeutschlands und Berlins vorbehalte. Dann aber kam er zu seinem Hauptanliegen. Er suchte Gromykos Interesse für einen Modus vivendi zu wecken und regte an, sich auf ein Vorgehen zu einigen, wie man Meinungsverschiedenheiten konfliktfrei handhaben könne. Anscheinend dachte er an ein Abkommen, das trotz fehlender Übereinstimmung in Grundsatzfragen über Regeln des praktischen Umgangs miteinander geschlossen werden würde, als er fortfuhr, ohne eine dauerhafte Regelung der deutschen Frage werde langfristig keine Ruhe in Europa eintreten. Er widersprach der zentralen Begründung für die gestellten sowjetischen Forderungen, als er hinzufügte, die militärische Präsenz der Westmächte - wie übrigens auch der Sowjetunion - sei ein wichtiges Hemmnis, das die verfeindeten Deutschen von friedensgefährdenden Abenteuern abhalte. Dadurch werde die Situation stabilisiert. Rusk erklärte weiter, es hänge sehr viel davon ab, ob Kennedy und Chruschtschow eine Basis wechselseitigen Verstehens fänden, und betonte, die Amerikaner verwendeten alle Phantasie darauf, geeignete Voraussetzungen dafür zu schaffen. Es sehe aber nicht so aus, als ob das gelinge. Gromyko ignorierte den Appell und äußerte sich enttäuscht darüber, daß die USA die Räumung West-Berlins und die Aufhebung des Besatzungsregimes verweigerten. ${ }^{95}$

\section{Aufbau einer Drohkulisse}

Auch Chruschtschow überhörte die Aufforderung, die prinzipiellen Differenzen beiseite zu lassen und eine Verständigung in den praktischen Fragen zu suchen. Ihn ärgerte, daß die USA auf seine Forderung nicht eingingen. Mit drohendem Unterton konfrontierte er Botschafter Thompson mit der Aussicht, daß der Dialog dem Ende zugehe. Es bleibe keine andere Wahl, als den Friedensvertrag mit

93 J. F. Kennedy an N.S. Chruščëv, 17. 7. 1962, ebd., S. 224-229.

94 Soderžanie besedy A. A. Gromyko s Raskom, 21. 7. 1962, AAN, KC PZPR XI A/81, Bl. 73-85; Soderžanie besedy A. A. Gromyko s Raskom, 22. 7. 1962, AAN, KC PZPR XI A/81, Bl. 90-102; Soderžanie besedy A. A. Gromyko s Raskom, 24. 7. 1962, AAN, KC PZPR XI A/81, Bl. 107-118; Telegram From the Secretary of State Rusk to the Department of State, 24. 7. 1962, ebd., S. 240242. Vgl. Soderžanie besedy A. A. Gromyko s Kuv de Mjurvilem, 21. 7. 1962, AAN, KC PZPR XI A/81, Bl. 86-89; Soderžanie besedy A. A. Gromyko s Chjumom, 23. 7. 1962, AAN, KC PZPR XI A/81, Bl. 103-106.

95 Telegram From the Secretary of State Rusk to the Department of State, 25. 7. 1962, ebd., S. 243252. 
der DDR zu schließen. Die Amerikaner meinten anscheinend, man könnte die Gespräche endlos fortführen. Das sei jedoch nicht annehmbar. ${ }^{96}$ Am 13. Juli erklärte Chruschtschow gegenüber Journalisten aus den USA, die von Washington verfügte Einberufung von Reservisten schrecke ihn nicht. Allen Gewaltandrohungen zum Trotz werde die UdSSR den Friedensvertrag unterzeichnen. Man werde sich zwar damit „nicht beeilen“, aber die Sache „auch nicht auf die lange Bank schieben“. Einen Zeitpunkt nenne er nicht. Auch gebe er „immer noch nicht die Hoffnung auf Vernunft und Einsicht bei der Regierung der USA und ihren Verbündeten“ auf. ${ }^{97}$ Auch in einer Rede am 18. August betonte der Kremlchef die Entschlossenheit zum Abschluß des Friedensvertrages. „Keinerlei Drohungen der Imperialisten" könnten die UdSSR davon abhalten. ${ }^{98}$

Wie aufgrund der vorangegangenen ablehnenden Reaktion auf Ulbrichts Drängen zu vermuten ist, dachte Chruschtschow auch diesmal nicht daran ernstzumachen. Nach wie vor war die Veränderung des Kräfteverhältnisses nicht eingetreten, die er im Januar dem Parteipräsidium als notwendig vor Augen gestellt hatte. Auch der Hinweis auf die „Geduld“, die er erklärtermaßen mit dem Westen vorerst noch üben wolle, deutet darauf hin, daß er die Voraussetzungen für den Abschluß des Friedensvertrages als noch nicht gegeben sah. Anscheinend hoffte er lediglich, Druck auszuüben. In gleichem Sinne suchte Dobrynin die amerikanische Seite mit der Aussicht zu beeindrucken, daß der Gesprächsfaden künftig abreißen werde. ${ }^{99}$ Zugleich wiederholte er in den Unterredungen mit Rusk seine früheren Aussagen nur noch routinemäßig und verzichtete auf neue Argumente und Nuancen - offenbar um Desinteresse an der behandelten Sache zu demonstrieren. Das Bemühen des amerikanischen Außenministers, ihm die Position der USA plausibel zu machen, geriet so zum Monolog. Die sinnlos gewordenen Gespräche wurden beendet. ${ }^{100}$ Zuvor hatte Dobrynin noch vage angedeutet, es werde irgendetwas geschehen. ${ }^{101}$ Wie es scheint, sollte die Führung in Washington den Eindruck gewinnen, sie müsse sich auf Schlimmes gefaßt machen, wenn sie nicht erhebliche Zugeständnisse anbiete.

In Berlin gab sich die sowjetische Seite den Anschein, daß sie die Weichen zur Aufhebung aller Überreste der Okkupationszeit stelle. Wie das Moskauer Verteidigungsministerium am 23. August erklärte, wollte es mit der Auflösung der Stadtkommandantur dem Eindruck entgegentreten, „als ob immer noch eine VierMächte-Kommandantur in Berlin existiere. “ Der Westen suche damit den Fortbestand des Besatzungsregimes in West-Berlin zu rechtfertigen, obwohl diese „im Ergebnis der separaten Handlungen der Westmächte“ längst nicht mehr bestehe.

96 Telegram From the Embassy in the Soviet Union to the Department of State, 26. 7. 1962, ebd., S. $253 \mathrm{f}$.

${ }_{97}$ Gespräch Chruščëvs mit amerikanischen Journalisten, 13. 7. 1962, in: Dokumente zur Deutschlandpolitik, IV, 8/2, S. 847 f.

98 Rede Chruščëvs auf der Großveranstaltung zu Ehren der zurückgekehrten sowjetischen Kosmonauten, 18. 8. 1962, in: Pravda, 19. 8. 1962.

${ }_{99}$ Memorandum of Conversation [Erörterung des Gesprächs Rusk - Dobrynin vom 8. 8. 1962], 9. 8. 1962, ebd., S. 264.

100 Memorandum of Conversation, 9. 8. 1962, ebd., S. 262-266; Memorandum of Conversation, 13. 8. 1962, ebd., S. 270 f.; Memorandum of Conversation, 21. 8. 1962, ebd., S. 278 f.

101 Memorandum of Conversation [Erörterung des Gesprächs Rusk - Dobrynin vom 8. 8. 1962], 9. 8. 1962, ebd., S. 264. 
Die nunmehr verfügte Maßnahme entspreche „voll und ganz der konsequent von der Sowjetunion verfolgten Politik zur Beseitigung der Überreste des zweiten Weltkrieges in Europa“. Der ausdrückliche Hinweis, daß zugleich der Abschluß des Friedensvertrages und eine darauf fußende Normalisierung der Lage in WestBerlin vorgesehen seien, verstärkte den Eindruck, daß der Kreml mit der Auflösung der Stadtkommandantur den Vier-Mächte-Status generell zu beseitigen sich anschickte. ${ }^{102}$

Genauere Angaben über seine Absichten machte Chruschtschow gegenüber dem österreichischen Außenminister Kreisky in einer Unterhaltung, bei der er sicher war, daß ihr Inhalt den Amerikanern über Willy Brandt bekannt werden würde. Er sei „noch eine gewisse Zeit bereit“, über die Fragen West-Berlins zu sprechen. „Doch die Plattform dafür wird immer enger. Man kann sagen, daß sie bereits sehr eng geworden ist." Nach Ablauf der verbliebenen Zeit werde die Sowjetunion „den Friedensvertrag unterzeichnen und die militärische Verbindung [der Westmächte] mit West-Berlin unterbrechen.“ Man werde „keine Blockade erklären“. An der „Verbindung für den Transport von Lebensmitteln und die übrige Versorgung" solle sich nichts ändern. Auch werde "die Nichteinmischung gewahrt bleiben“. Der Westen drohe zwar mit Krieg, doch sei dies „unbedacht“, denn ihm fehle die nötige Macht. Der Kremlchef erklärte wissenswidrig, die UdSSR sei stärker. Wenn die andere Seite wegen zwei Millionen West-Berlinern die ganze Welt in einen Nuklearkrieg stürzen wolle, sei klar, wer im Recht und wer im Unrecht sei. Für Verrückte könne man freilich „keine Garantie übernehmen". Der Westen habe vielleicht schon den Verstand verloren und beginne einen Krieg. Dann jedoch werde „er selbst die Früchte ernten““.103

Demnach war Chruschtschow zwar zu allem entschlossen, wollte aber doch noch zuwarten. Dem entsprach es, daß die UdSSR bei Auflösung der Berliner Kommandantur klar machte, sie verzichte vorerst nicht auf die Vier-Mächte-Zuständigkeiten (wie vor allem die Kontrolle des militärischen Zugangsverkehrs der drei westlichen Staaten), sondern nehme sie künftig durch den Oberbefehlshaber der sowjetischen Truppen in Deutschland wahr.104 Der Versuch, die amerikanische Führung mit der Perspektive eines Abbruchs der Gespräche und des folgenden Friedensvertragsabschlusses zu beeindrucken, zeitigte wenig Wirkung. In Washington war man auf die Eventualität des Separatvertrags gefaßt und sah für diesen Fall Maßnahmen vor, welche die Folgen für West-Berlin abwenden oder zumindest minimieren würden. ${ }^{105}$ Währenddessen bemühte sich Chruschtschow

102 Kommuniqué des Ministeriums für Verteidigung der UdSSR, 23. 8. 1962, in: Freundschaft DDRUdSSR. Dokumente und Materialien, [Ost-]Berlin 1965, S. $281 \mathrm{f}$.

103 Aufzeichnung ohne Überschrift und mit handschriftlich vermerktem Datum „10.8. 1962“ über Gespräch Chruščëv - Kreisky, LArchB, B Rep 002, Nr. 7993b, Bl. 627 f.

104 Kommuniqué des Ministeriums für Verteidigung der UdSSR, 23. 8. 1962, in: Freundschaft DDRUdSSR, a.a.O., S. 282. Der Vorbehalt wurde auch gegenüber der DDR ausdrücklich formuliert: Besuch von Botschafter Pervuchin in Verbindung mit Abschaffung der sowjetischen Garnison in Berlin, 17. 8. 1962, PA-MfAA, G-A 478, Bl. 74f.; Aktenvermerk Krolikowski über Gespräch zwischen Staatssekretär Winzer und Botschafter Pervuchin am 20. 8. 1962, PA-MfAA, G-A 478, Bl. 78-84/A 546, Bl. 307-313; Aufzeichnung ohne Überschrift und ohne Datum [22.8. 1962 oder kurz danach], PA-MfAA, G-A 478, Bl. $76 \mathrm{f}$.

105 Memorandum From Secretary of State to President Kennedy, 2. 8. 1962, in: FRUS 1961-1963, XV, S. 257-262. 
um Unterstützung der UNO. Generalsekretär U Thant ließ sich zwar dazu überreden, die sowjetische Berlin-Politik als friedensdienlich zu bezeichnen, aber als internationaler Beamter sah er sich dem Prinzip der Neutralität zwischen den streitenden Seiten verpflichtet und war daher zu keiner Initiative nach sowjetischen Vorstellungen bereit. 106

\section{Der Hebel in der Hinterhand}

Nachdem Chruschtschow bei der Aktion gegen die Luftkorridore im März hatte erkennen müssen, daß er selbst damit nicht weiterkam, ist es fraglich, ob er sich weiter von verbalen Warnungen ernstlichen Erfolg versprach. Mit den Hinweisen auf ein drohendes endgültiges Scheitern der Gespräche könnte er aber bezweckt haben, Washington allmählich auf eine grundlegend veränderte Lage einzustimmen, die er in einigen Monaten herbeizuführen hoffte. Ende Mai 1962 hatte er den Entschluß gefaßt, Nuklearraketen in Kuba zu dislozieren. Anschließend wurde der Transport unter strengster Geheimhaltung vorbereitet und durchgeführt. Ende Juli kamen die ersten Schiffe auf der Karibik-Insel an. ${ }^{107}$ Es war vorauszusehen, daß sich die UdSSR nach Abschluß der Aktion im Spätherbst in einer weit besseren militärischen Position gegenüber den USA befinden würde als bisher. Die - von amerikanischer Seite im Oktober 1961 öffentlich festgestellte - Unterlegenheit bei den Kernwaffen, mit denen beide Mächte das Gebiet der jeweils anderen erreichen konnten, würde dann durch die Mittelstreckensysteme auf Kuba ausgeglichen sein, welche die nahen USA massiv bedrohten. ${ }^{108}$

Chruschtschow hatte zwar bei seiner Entscheidung viele Gesichtspunkte im Auge, ${ }^{109}$ und durch die bisher verfügbaren Akten ist nicht belegt, daß der ungelöste Berlin-Konflikt ein zentrales Motiv darstellte. Auch wenn das nicht der Fall gewesen sein sollte, konnte aber nicht ausbleiben, daß er nach gefaßtem Beschluß erkannte, daß sich die angestrebte Veränderung des militärischen Kräfteverhältnisses unausweichlich auf den weiteren Verlauf der Auseinandersetzung auswirkte. Zudem gibt es konkrete Anzeichen dafür, daß der Kremlchef damit rechnete, nach Abschluß der Raketenstationierung auf Kuba den Forderungen nach Friedensvertrag und Freistadtregelung überzeugend Nachdruck verleihen zu können. Dazu gehören die erwähnten dunklen Andeutungen Gromykos über das Ungemach, das die USA bei weiterem Festhalten an ihrem Standpunkt treffen werde, und die ebenfalls bereits erwähnten Bemerkungen, die sowjetische Geduld werde in absehbarer Zeit ein Ende haben. Nach langen Ausführungen über die Kuba-Frage deutete eine TASS-Erklärung vom 12. September an, welcher Zeitpunkt ins Auge gefaßt war. Den Vereinigten Staaten falle es wegen der Kongreßwahlen im November angeblich schwer, über einen Friedensvertrag zu verhan-

\footnotetext{
106 Protokoll des Gesprächs Chruščëv - U Thant, 28. 8. 1962, in: Istočnik, 6/2003, S. 151-159.

107 A. Fursenko/T. Naftali, a.a.O., S. 172-176.

108 Harald Biermann, Die Kuba-Krise: Höhepunkt oder Pause im Kalten Krieg? in: Historische Zeitschrift, Bd. 273 (2001). S. 638-648, hält - aufgrund jedoch nur westlicher Quellen - diese Überlegung für ausschlaggebend.

109 Näheres zur Vorgeschichte des Entschlusses bei A. Fursenko/T. Naftali, a.a.O., S. 149-172.
} 
deln. Das wolle die sowjetische Regierung berücksichtigen. ${ }^{110}$ Danach, so war zu entnehmen, werde die Zeit gekommen sein, von den Amerikanern eine Entscheidung zu verlangen. Später ließen zudem Chruschtschow und Gromyko Washington ausdrücklich wissen, daß sie dann einen ,aktiven Dialog " beginnen wollten. ${ }^{111}$ Das war genau der Zeitpunkt, zu dem der Abschluß der Raketenaufstellung auf Kuba vorgesehen war.

Natürlich konnte der Kreml zunächst nicht deutlicher aussprechen, was er im Sinne hatte, hing doch das Gelingen des Stationierungsplans - und damit auch der Erfolg der danach geplanten Gespräche - entscheidend davon ab, daß die Amerikaner die Raketen auf Kuba erst entdeckten, wenn deren Aufbau beendet war. War die Dislozierung erst einmal zur vollendeten Tatsache geworden, ließ sie sich nur noch mit Gewalt rückgängig machen. Die Führung in Washington würde sich dann dessen bewußt sein müssen, daß ein militärischer Einsatz gegen die Raketenstellungen auf der Karibikinsel automatisch Krieg mit der UdSSR bedeutete, also mit Gewißheit auch das eigene Land unabsehbarer Vernichtung aussetzte. Unter diesen Umständen, so kalkulierte Chruschtschow, werde sich die amerikanische Regierung lieber mit der veränderten Relation der Kräfte abfinden. Dann blieb ihr kaum etwas anderes übrig, als die exponierte Position in Berlin zu räumen. Die Offensivraketen auf Kuba erschienen daher geeignet wahrzumachen, was dem sowjetischen Führer Anfang Januar auf der Sitzung des Parteipräsidiums als langfristige Lösung des Konflikts vor Augen gestanden hatte.

Diese Erwartung könnte erklären, wieso Gromyko nach einem Gespräch, in dem Rusk das originäre Recht auf Präsenz und Zugang vehement und zuletzt mit ungewohnter Schärfe verteidigt hatte, ${ }^{112}$ gleichwohl intern die Ansicht äußerte, man bewege sich auf eine Vereinbarung zu, die West-Berlin einen anderen Status zuweisen und eine den Erfordernissen der DDR-Souveränität voll entsprechende Zugangsbehörde etablieren werde. ${ }^{113}$ Die Zuversicht, die Chruschtschow und die eingeweihten sowjetischen Spitzenfunktionäre ausstrahlten, übertrug sich auf die nachgeordneten Chargen in Moskau. Ein Angehöriger des Außenministeriums, der an der Vorbereitung der Deutschland-Politik maßgeblich mitwirkte, urteilte in einer Ausarbeitung für den zuständigen stellvertretenden Minister, die westlichen Regierungen sähen sich trotz gegenteiliger Ermahnungen aus Bonn immer mehr dazu genötigt, „mit der realen Situation in Berlin zu rechnen." Der VierMächte-Status bestehe faktisch schon nicht mehr.114

110 Pokončit' s politikoj provokacii. Zajavlenie TASS, in: Pravda, 12. 9. 1962.

111 N. S. Chruščëv an J. F. Kennedy (Auszug der Ausführungen zu Friedensvertrag und West-Berlin), o.D. [28. 9. 1962], in: FRUS 1961-1963, XV, S. 338; Telegram From the Embassy in the Soviet Union to the Department of State [Gespräch Chruščëv - Botschafter Kohler], 16. 10. 1962, ebd., S. 359-361; Memorandum of Conversation [Kennedy - Gromyko], 18. 10. 1962, ebd., S. 371.

112 Memorandum of Conversation, 18. 10. 1962, ebd., S. 376-387.

113 Gespräch A. A. Gromyko - W. Ulbricht, 23. 10. 1962, AVPRF, 0742, 7, 51, 4, Bl. 48-62.

${ }^{114}$ I. Kuz'myčev, O pozicii pravitel'stva i političeskich partij FRG po mirnomu uregulirovaniju i voprosu o Zapdanom Berline (Anlage zum Schreiben von A. Smirnov an I. I. Il'ičëv, 29. 9. 1962), AVPRF, 0757, 7, 57, 21, Bl. 58. 


\section{Meinungsaustausch im September und Oktober}

Nach langer Pause kam der sowjetisch-amerikanische Meinungsaustausch Ende September wieder in Gang. In einem Schreiben an Kennedy zu den Rüstungskontrollverhandlungen appellierte Chruschtschow an diesen, sich mit den unterbreiteten Vorschlägen einverstanden zu erklären. Der Präsident müsse doch ebenfalls erkennen, daß West-Berlin die wechselseitigen Beziehungen „fiebrig“ mache, solange dort keine „vernünftige Lösung“ erreicht sei. Der Kremlchef fügte hinzu, derzeit gebe es keine andere Möglichkeit, als das Problem durch Unterzeichnung des Friedensvertrages zu lösen. Auf dieser Grundlage könnte für eine gewisse - voraussichtlich nur kurze - Zeit ein symbolisches Truppenkontingent unter UNO-Flagge in West-Berlin stationiert werden, um, wie Kennedy meine, die Freiheit der Bevölkerung zu garantieren. Keine Seite hätte einen Prestigeverlust; der Spannungsherd wäre beseitigt.

Der Kremlchef verband seine Ausführungen mit Polemik gegen alle Akteure im Westen, die sich gegen seine Vorstellungen wandten. „Einige“ seien am Fortbestand des Spannungsherdes und daran interessiert, es nicht zu einer Normalisierung des sowjetisch-amerikanischen Verhältnisses kommen zu lasssen. Vor allem Adenauer wolle den Konflikt. Chruschtschow ging so weit, ihm zu unterstellen, er setze Hitlers „Lebensraum“-Politik fort, gegen die man im Zweiten Weltkrieg gemeinsam gekämpft habe. Um dem einen Riegel vorzuschieben, müsse man zu einer Einigung über West-Berlin gelangen, wo doch nur noch die Anwesenheit der westlichen Truppen strittig sei. ${ }^{115}$ Der amerikanische Außenminister wandte sich im folgenden Gespräch mit seinem sowjetischen Amtskollegen nachdrücklich gegen die Unterstellung, der Präsident und andere westliche Führer machten sich zum Sprachrohr Adenauers, wenn sie dem Urteil über dessen Politik widersprächen. Gromyko forderte von den USA, von Bonn abzurücken und die Beziehung zum Kreml durch Eingehen auf dessen Forderungen zu entspannen. Die Amerikaner sollten sich um den Frieden bemühen, statt an West-Berlin als „Militärbasis der NATO" festzuhalten.116

Chruschtschow warf Kennedy am 16. Oktober im Gespräch mit dem neu nach Moskau entsandten US-Botschafter Kohler vor, er habe die Atmosphäre durch Einberufung von 150000 Resevisten angeheizt. Er wolle aber seinerseits dem Beispiel nicht folgen. Weiter sprach er von einer „törichten“ Bekundung amerikanischer Kriegsbereitschaft für den Fall, daß die UdSSR den Friedensvertrag mit der DDR schließe. Das würde unausweichlich ein nuklearer Krieg werden. Wer den anfange, sei entweder irre oder feige. Adenauer rede so, aber der sei alt und verliere allmählich den Verstand. Nach dieser Polemik äußerte sich der Kremlchef zur Sache. Nur die Frage der Truppenstationierung in West-Berlin sei noch offen. Einen neuen Akzent setzte sein erstmaliger Hinweis, der Zugang sei nach sowjetischer Ansicht auf jeden Fall gewährleistet, ob es nun darüber einen Vertrag gebe

115 N. S. Chruščëv an J. F. Kennedy (Auszug der Ausführungen zu Friedensvertrag und West-Berlin), o.D. [28. 9. 1962], in: FRUS 1961-1963, XV, S. 337 f. Vgl. den vollständigen Text des Schreibens in: FRUS 1961-1963, Bd. VI: Kennedy-Khrushchev Exchanges, Washington 1996, S. 152-161.

116 Sowjetische Berichtswiedergabe über das Gespräch Gromyko - Rusk vom 6. 10. 1962 ohne Überschrift und Datum (russ.), AAN, KC PZPR XI A/81, Bl. 136-151. 
oder nicht. Das sollte vermutlich die USA beruhigen, falls es Ende des Jahres trotz der Raketen auf Kuba zu keiner Einigung kam und der Kreml daraufhin den Friedensvertrag mit der DDR unterzeichnete. Im übrigen erklärte Chruschtschow den Streit über die Zusammensetzung der Truppen in West-Berlin für leicht lösbar. Es komme nur darauf an, daß sie unter der Flagge der UNO stünden und nicht nur von westlichen Staaten gestellt würden. Zudem seien Stützpunkte und Soldaten ohnehin nicht mehr zeitgemäß. Man solle am besten auf beides verzichten und sich auf Raketen stützen. Die aber könnten die USA doch vom eigenen Territorium aus starten. ${ }^{117}$

Hinter Chruschtschows Appell an Kennedy verbarg sich ein unverändert kompromißloser Standpunkt, wie Gromyko zwei Tage später in Gesprächen mit dem Präsidenten und dem Außenminister der USA deutlich machte. Der scharfe Gegensatz betraf nicht nur die Präsenz in West-Berlin. Dort ließ die UdSSR nach wie vor kein originäres Recht der Westmächte gelten und wollte nur einen kurzzeitigen Ersatz für ihre Truppen in Form eines symbolischen Kontingents von UNOSoldaten ohne politische Vollmachten zulassen. Auch in der angeblich bereits gelösten Zugangsfrage gab es einen unüberbrückbaren Dissens. Der Kreml gestand der Zugangsbehörde nur die Rolle eines machtlosen Vermittlers bei Transitstreitigkeiten zu und bestand darauf, daß diese dem Zwang zur Einstimmigkeit unterliegen müsse, was ihr von vornherein die Fähigkeit zu Entscheidungen gegen das Vorgehen der DDR nehmen mußte. In Übereinstimmung damit wurde die ostdeutsche Souveränität zum obersten Leitprinzip erklärt. Den amerikanischen Vorschlag, man könne das Souveränitätsbedürfnis der DDR befriedigen, indem man ihr Recht zu vertraglicher Transitgewährung anerkannte, und zugleich die Freiheit des Zugangs gewährleisten, indem man den Verzicht der ostdeutschen Seite auf Eingriffe in den Verkehr auf den Transitstrecken in das Abkommen hineinschrieb, lehnte Gromyko scharf ab. Eine Regelung, welche die Souveränität der DDR zwar der Form nach respektiere, sie aber in der Sache verletze, komme nicht in Betracht. Der Dialog der beiden Außenminister endete mit heftigen wechselseitigen Vorwürfen. ${ }^{118}$

Trotzdem glaubte Gromyko positive Teilresultate feststellen zu können, als er Ulbricht über den Meinungsaustausch mit den Amerikanern berichtete. Kennedy sei zwar, was die von beiden Seiten für zentral erachtete Frage der militärischen Präsenz in West-Berlin betreffe, nicht zum Abzug der Garnison bereit, wolle aber die Rolle, die Aufgaben und den Rechtsstatus der westlichen Truppen überprüfen, wie er nach vorangegangenen amerikanischen und britischen Andeutungen seinerseits klargestellt habe. Der Präsident denke an eine Übereinkunft, welche die Truppen auf veränderter Grundlage und mit verändertem Status in der Stadt belasse. Es gehe also um eine Neuregelung, die das bisherige Besatzungsregime ersetze. Gromyko wies auf frühere amerikanische Anregungen hin, daß man die Truppen der drei Westmächte vielleicht UNO-Truppen nennen könnte. Das lasse sich diskutieren.

117 Telegram From the Embassy in the Soviet Union to the Department of State, 16. 10. 1962, ebd., S. 359-362.

118 Memorandum of Conversation [Rusk - Gromyko], 18. 10. 1962, ebd., S. 376-387; Memorandum of Conversation [Kennedy - Gromyko], 18. 10. 1962, ebd., S. 370-376. 
In der Zugangsfrage bezog er sich auf ein Gespräch mit dem britischen Außenminister Lord Home. Dieser habe erwogen, zwischen militärischem und zivilem Zugang zu unterscheiden. Die darin liegende Möglichkeit, für die DDR beim Ziviltransit mehr Eingriffsrechte zu fixieren, hielt Gromyko für interessant. Da es sich nach sowjetischer Absicht dabei - anders als bei der Vereinbarung über die Militärtransporte, die nach dem vorgesehenen Ende der westlichen Präsenz hinfällig werden würde - um eine Dauerregelung handeln sollte, konnte man versuchen, die westliche Seite mit Konzessionen beim Militärverkehr zur Anerkennung der vollen ostdeutschen Verfügungsgewalt über den Ziviltransit zu bewegen. Die Wahrscheinlichkeit dafür schien dadurch erhöht, daß die sowjetische Forderung nach uneingeschränkter DDR-Souveränität von Rusk nicht ausdrücklich zurückgewiesen worden war. Ebenso sah Gromyko Grund zur Hoffnung darin, daß die USA Kontakte zwischen beiden deutschen Staaten akzeptieren wollten. Überdies glaubte er, der Westen habe noch nicht alle Zugeständnisse auf den Tisch gelegt. Demzufolge war die UdSSR auf dem besten Weg, sich in den Verhandlungen noch mehr durchzusetzen, als es bis dahin der Fall war. ${ }^{119}$

Der Kreml war bemüht, die Vertreter der DDR von seiner vollen Entschlossenheit zu überzeugen. Es gelte, endlich „einen Schlußstrich unter den Kriegszustand zu ziehen“ und „die Existenz von gewissen Überresten des Zweiten Weltkriegs“, vor allem des westlichen Besatzungsregimes, zu beseitigen, um die Welt vor Völkerverhetzung und Krieg zu bewahren. West-Berlin dürfe kein „NATO-Stützpunkt“ bleiben. Nur mit dem Aufenthalt „symbolischer UNO-Truppen“ sei die UdSSR einverstanden. Auch von einer „Anerkennung der zwei deutschen Staaten“ und ihrer Aufnahme in die UNO war die Rede. Zwischentöne ließen freilich vermuten, daß der sowjetische Wille nicht ganz so fest war, wie suggeriert wurde. Die Sorge um Abrüstung und die kubanische Revolution trat in Konkurrenz zu den Deutschland- und Berlin-Zielen, auf die sich früher die alleinige Aufmerksamkeit gerichtet hatte, und die Drohung gegenüber den Westmächten wurde dahingehend abgeschwächt, daß man für den Fall von deren Verweigerung den Abschluß des Friedensvertrags mit der DDR nicht fest zusagte, sondern nur als möglich bezeichnete. ${ }^{120}$

\section{Konflikte um Berlin und Krise um Kuba}

Im Spätsommer und Frühherbst verschärften sich die Spannungen in Berlin. Der Tod des Flüchtlings Peter Fechter, der, von ostdeutschen Schüssen getroffen, am 17. August an der Mauer qualvoll verblutete, rief überall im Westen heftige Empörung hervor. Der Zorn der West-Berliner Bevölkerung richtete sich unter anderem gegen sowjetische Militärs, die sich in der Stadt zeigten. Wiederholt wurden umherfahrende Soldatenbusse mit Steinen beworfen. Als der Aufruhr drei Tage lang angehalten hatte, schickte der Oberbefehlshaber der Truppen in Deutschland, Ge-

119 Gespräch A. A. Gromyko - W. Ulbricht, 23. 10. 1962, AVPRF, 0742, 7, 51, 4, B1. 48-62.

120 Die sowjetische Haltung zu einigen brennenden Problemen der Weltpolitik, 4. 10. 1962 (handschriftliche Einfügung), PA-MfAA, A-100, Bl. 105-114. 
neral Jakubowskij, mit Billigung des Kreml gepanzerte Mannschaftstransporter nach West-Berlin. Erst nach einigen Wochen, als sich die Lage beruhigt hatte, setzte er auf westliches Verlangen für die Fahrten in die Westsektoren wieder Busse ohne militärische Schutzvorrichtungen ein.121

Am 21. September stoppte die DDR-Volkspolizei den Zivilverkehr auf der Autobahn zwischen Helmstedt und West-Berlin mehrere Stunden lang. Drei Tage danach verlangte das sowjetische Personal an einer Übergangsstelle nach der Stadt entgegen den bestehenden Regeln, die amerikanischen Soldaten müßten zur Prüfung ihrer Identität aus den Fahrzeugen aussteigen. Als der Konvoi nicht Folge leistete, wurde die Abfertigung verweigert. Nachdem es eine Zeitlang nicht zur Einigung gekommen war, wollte der stellvertretende Oberkommandierende der USA in Europa, General Wheeler, die Truppe schon zur Weiterfahrt ohne Abfertigung veranlassen, doch in diesem Augenblick gab die sowjetische Seite endlich nach. Am nächsten Tag brachten MIG-Jäger in den Luftkorridoren durch nahes Heranfliegen eine amerikanische Militärmaschine und ein französisches Linienflugzeug in akute Gefahr. Verteidigungsminister McNamara sah sich zu der Erklärung veranlaßt, daß die USA notfalls sogar den Einsatz von Kernwaffen nicht scheuen würden, um Berlin zu verteidigen. ${ }^{122} \mathrm{Im}$ Kreml hieß es, in den Geprächen mit den Amerikanern sei eine „Pause“ eingetreten. Uneingeschränkt wurde aufrechterhalten, die westlichen Truppen könnten dort „nicht aufgrund der gegenwärtigen Rechtslage verbleiben“. Man erwartete, daß die USA die Initiative zur Fortsetzung des Dialogs ergreifen würden.123

Chruschtschow scheint diese Hoffnung darauf gegründet zu haben, daß die seit Monaten in Gang befindliche Dislozierung von Nuklearraketen und anderen Kernwaffen auf Kuba zu Ende gebracht werden könne, ohne daß die Amerikaner die Sache vorher entdeckten. Damit werde ein total verändertes Kräfteverhältnis entstehen, das die USA zu einer baldigen Beendigung des Streits um Berlin und damit zum Nachgeben nötige. Es gelang der UdSSR jedoch nicht, die Stationierung vor ihrer Entdeckung durch die Amerikaner abzuschließen und sie damit diesen als schon vollendete, nicht mehr rückgängig zu machende Tatsache zu präsentieren. Am 16. Oktober wurden Kennedy Fotografien vorgelegt, die den Bau von Raketenstellungen auf der Karibikinsel zeigten. Nachdem man sich in Washington vergewissert hatte, daß es sich nicht um Luftabwehr-, sondern Offensivsysteme handelte, wandte sich der Präsident am 22. Oktober zunächst an den Kremlchef und dann an die Öffentlichkeit. Er könne die Bedrohung nicht hinnehmen und verhänge $\mathrm{zu}$ deren Abwehr eine Blockade gegen Kuba. ${ }^{124}$ Chruschtschow geriet in allergrößte Sorge. Auf einer eilig einberufenen Nachtsitzung des Parteipräsidiums setzte er die „Berlin- und Kuba-Frage“ auf die Tagesordnung125 und machte damit deutlich, daß er beides eng miteinander verknüpft sah.

121 J. C. Ausland, a.a.O., S. 63-66.

122 Ebd., S. 67.

123 Botschafter Pervuchin im Gespräch mit seinem ungarischen Amtskollegen: József Kárpáti an Antal Apro/Dezsö Nemes/Imre Hollai/János Szita (ungar.), 29. 9. 1962, MOL 288.f. 32/1962/11ö.e., B1. 217.

124 H. Biermann, a.a.O., S. 649-655.

125 Protokoll der Sitzung des Präsidiums des ZK der KPdSU, 22. 10. 1962, in: A. A. Fursenko (otv. red.), Archivy Kremlja, a.a.O., S. 617 f. 
In Washington fürchtete man, der sowjetische Führer werde die Krise in der Karibik zum Schlag gegen West-Berlin nutzen. ${ }^{126}$ Eine offensive Aktion zur Beseitigung der westlichen Präsenz im Schatten einer anhaltenden Konfrontation um Kuba, welche Aufmerksamkeit und Streitkräfte der USA gebunden hätte, scheint in Moskau niemand erwogen zu haben. Chruschtschow erhielt nur die Anregung, sich gegen den Druck in Kuba durch Gegendruck in Berlin zu wehren, aber auch das lehnte er als „Abenteuer“ ab.127 Er wollte die Hochspannung nicht ausweiten, sondern beenden. Ungeachtet des kurz zuvor verschärften Konflikts um die Stadt, blieb es dort vollkommen ruhig. ${ }^{128}$ Kennedy beantwortete zwar den Abzug der sowjetischen Raketen von der Karibikinsel mit Gegenkonzessionen, doch wurde das Resultat allgemein als großer Sieg der USA angesehen. Diese hatten den sowjetischen Versuch abgewehrt, das militärische Kräfteverhältnis entscheidend zu verändern. Chruschtschow blieb die erstrebte global-strategische Parität mit der Führungsmacht des Westens versagt. Das war in der Tat das ausschlaggebende Ergebnis. Damit entfiel auch die Aussicht, die Amerikaner in Berlin zur Aufgabe ihres Widerstandes gegen Friedensvertrag und Freistadtregelung zu nötigen.

126 C. Münger, a.a.O., S. 202-204, 239.

127 Nach Oleg Trojanovskij, Karibskij krizis - vzgljad iz Kremlja, in: Meždunarodnaja žizn', 3-4/ 1992, S. 172, kam eine solche Anregung vom stellv. Außenminister V. Kuznecov. Herbert Häber, Die Deutschlandpolitik der SED, in: Reinhard Hübsch (Hrsg.), „Hört die Signale!“ Die Deutschlandpolitik von KPD/SED und SPD 1945-1970, Berlin 2002, S. 89, erinnert sich, daß sich auch Botschafter Dobrynin in diesem Sinne äußerte.

128 Rusk, Assessment of Current Soviet Intentions [mit einleitendem Rückblick auf das sowjetische Verhalten während der Kuba-Krise], 7.11. 1962, in: FRUS 1961-1963, S. 420 f.; J. C. Ausland, a.a.O., S. 71. 